\title{
Insulin Reveals Akt Signaling as a Novel Regulator of Norepinephrine Transporter Trafficking and Norepinephrine Homeostasis
}

\author{
Sabrina D. Robertson, ${ }^{1,3}$ Heinrich J. G. Matthies, ${ }^{1,3}$ W. Anthony Owens, ${ }^{4}$ Vidiya Sathananthan, ${ }^{1}$ \\ Nicole S. Bibus Christianson, ${ }^{1}$ J. Phillip Kennedy, ${ }^{2}$ Craig W. Lindsley, ${ }^{2}$ Lynette C. Daws, ${ }^{4 \star}$ and Aurelio Galli ${ }^{1,3 *}$ \\ Departments of ${ }^{1}$ Molecular Physiology and Biophysics, and ${ }^{2}$ Pharmacology, ${ }^{3}$ Center for Molecular Neuroscience, Vanderbilt University, Nashville, \\ Tennessee 37232, and ${ }^{4}$ Department of Physiology, University of Texas Health Science Center, San Antonio, Texas 78229
}

\begin{abstract}
Noradrenergic signaling in the CNS plays an essential role in circuits involving attention, mood, memory, and stress as well as providing pivotal support for autonomic function in the peripheral nervous system. The high-affinity norepinephrine (NE) transporter (NET) is the primary mechanism by which noradrenergic synaptic transmission is terminated. Data indicate that NET function is regulated by insulin, a hormone critical for the regulation of metabolism. Given the high comorbidity of metabolic disorders such as diabetes and obesity with mental disorders such as depression and schizophrenia, we sought to determine how insulin signaling regulates NET function and thus noradrenergic homeostasis. Here, we show that acute insulin treatment, through the downstream kinase protein kinase B (Akt), significantly decreases NET surface expression in mouse hippocampal slices and superior cervical ganglion neuron boutons (sites of synaptic NE release). In vivo manipulation of insulin/Akt signaling, with streptozotocin, a drug that induces a type 1-like diabetic state in mice, also results in aberrant NET function and NE homeostasis. Notably, we also demonstrate that Akt inhibition or stimulation, independent of insulin, is capable of altering NET surface availability. These data suggest that aberrant states of Akt signaling such as in diabetes and obesity have the potential to alter NET function and noradrenergic tone in the brain. Furthermore, they provide one potential molecular mechanism by which Akt, a candidate gene for mood disorders such as schizophrenia and depression, can impact brain monoamine homeostasis.
\end{abstract}

\section{Introduction}

Appropriate regulation of critical brain functions such as learning, memory, attention, sleep, mood, and stress depend on the fidelity of noradrenergic signaling in the nervous system. The norepinephrine transporter (NET) is fundamental for maintaining this fidelity by controlling both the duration and strength of NE signaling through its reuptake of synaptic NE (Iversen, 1971; Pacholczyk et al., 1991; Bönisch and Brüss, 2006). Indeed, disruption of NET function has been shown to directly impact both autonomic function and mental health (Ganguly et al., 1986; Klimek et al., 1997; Rumantir et al., 2000; Shannon et al., 2000; Hahn et al., 2003, 2005, 2008, 2009; Kim et al., 2006; Haenisch et al., 2008).

Prior studies illustrate that NET function is dynamically regulated both by manipulation of transporter turnover rate and by

\footnotetext{
Received Jan. 6, 2010; revised June 18, 2010; accepted June 22, 2010.

This work was supported by National Institutes of Health Grants MH058921 and DA13975 (A.G.), DA14684 (A.G., L.C.D.), and MH084755 (S.D.R.). We thank members of the Galli, Blakely, Colbran, and Kenworthy laboratories for useful discussion. We also acknowledge Dr. J. R. Goldenring for use of the anti-Rab11a antibody, Dr. R.D. Blakely for the use of the stably transfected hNET cell line, and the Vanderbilt Neurochemistry Core.

*L.C.D. and A.G. contributed equally to this work.

Correspondence should be addressed to either Aurelio Galli, Room 7124, Medical Research Building III, Center for Molecular Neuroscience, Nashville, TN 37232-8548, E-mail: aurelio.galli@vanderbilt.edu; or Lynette C. Daws, Department of Physiology, University of Texas Health Science Center, 7703 Floyd Curl Drive, San Antonio, TX 782293900,E-mail: daws@uthscsa.edu.

DOI:10.1523/JNEUROSCI.0126-10.2010

Copyright $\odot 2010$ the authors $\quad$ 0270-6474/10/3011305-12\$15.00/0
}

trafficking of the transporter to and from the plasma membrane (Apparsundaram et al., 1998a,b, 2001; Uchida et al., 1998; Miner et al., 2003; Sung et al., 2003; Jayanthi et al., 2004; Dipace et al., 2007). Importantly, previous studies implicate a clear role for insulin, a metabolic hormone, in the regulation of NET function. Indeed, insulin inhibits NE uptake in whole-brain neuronal cultures, dissociated brain cells, and whole-brain synaptosomes (Boyd et al., 1985, 1986; Masters et al., 1987; Raizada et al., 1988). Furthermore, Figlewicz et al. (1993) demonstrated the ability of nanomolar concentrations of acute insulin to decrease NE uptake from both hypothalamic and hippocampal slices. These studies were elegantly extended to demonstrate that insulin also inhibits NE uptake in PC12 cells, which endogenously synthesize NE and express NET (Figlewicz et al., 1993). Conversely, more recent studies have shown in different preparations that insulin increases NE uptake (Apparsundaram et al., 2001). Our studies, both in vitro and in vivo, indicate that insulin plays an inhibitory role in the regulation of NET function by controlling its surface availability. Moreover, we reveal that protein kinase B (Akt), a multifunctional kinase downstream of numerous signaling pathways including insulin, is required for this insulin regulation. Importantly, we also show that Akt activity potently regulates NET surface levels independently of changes in insulin status.

Diseases characterized by aberrant insulin and Akt signaling such as diabetes and obesity have a high comorbidity with monoamine-related mental disorders such as schizophrenia and depression (Mukherjee et al., 1989, 1996; Lustman and Clouse, 
2005; Zhao et al., 2006). Our data reveal, for the first time, Akt function as a potent regulator of NET activity/trafficking, and thus provide an interesting and plausible link between metabolic dysfunction and mood disorders. Considering the identification of Akt as a candidate susceptibility gene in schizophrenia and perhaps depression (Hsiung et al., 2003; Emamian et al., 2004; Karege et al., 2007; Arguello and Gogos, 2008), these data also provide a plausible molecular mechanism linking anomalous Akt function to altered monoamine homeostasis, which is characteristic of these disorders.

\section{Materials and Methods}

Cell culture and transfection. We gratefully acknowledge Dr. Randy Blakely (Vanderbilt University, Nashville, TN) for the gift of CHO cells stably transfected with human influenza hemagglutinin (HA)-tagged human NET (hNET cells). The cells were maintained in Ham's F12 Media/ $10 \% \mathrm{FBS} / \mathrm{L}-\mathrm{Glu} / \mathrm{pen} / \mathrm{strep}$. Cells were plated on poly-D-lysine-coated plates (Millipore Bioscience Research Reagents) for each experiment and incubated for 24-48 h before each experiment. Transient transfections with Akt-KD, a kinase dead (catalytically inactive) construct of Akt with the lysine at residue 179 replaced with an arginine (AKT-K179R) (Garcia et al., 2005), was graciously provided by Dr. R. Roth (Stanford University, Stanford, CA). Roche), and experiments on transfected cultures were performed $48 \mathrm{~h}$ after transfection. Mouse superior cervical ganglion neurons (SCGNs) were cultured according to Savchenko et al. (2003) (Matthies et al., 2009). Briefly, superior cervical ganglions were dissected from 1- to 3-d-old C57BL/6J mice and dissociated for $30 \mathrm{~min}$ in $3 \mathrm{mg} / \mathrm{ml}$ collagenase $/ 0.5 \mathrm{mg} / \mathrm{ml}$ trypsin, followed by $10 \%$ FBS in DMEM. Cells were plated and incubated with 3\% FBS in UltraCulture medium containing NGF for $2 \mathrm{~h}$ at $37^{\circ} \mathrm{C}$ to allow fibroblasts to adhere. Supernatant medium (containing SCG cells) was centrifuged, resuspended in medium supplemented with FBS, and cultured on poly-D-lysine- and collagen-coated glass-bottom plates for $14 \mathrm{~d}$ before experiments (treating with $1 \mu \mathrm{M}$ 5-fluoro-5-deoxyuridine after $24 \mathrm{~h}$ ).

Antibodies and other reagents. Monoclonal anti-mNET (NET-05) and monoclonal anti-hNET (NET 17-1) from MAb Technologies (Matthies et al., 2009), monoclonal anti- $\mathrm{Na}^{+} / \mathrm{K}^{+}$ATPase $\alpha$ subunit (Developmental Studies Hybridoma Bank), anti-Tyrosine Hydroxylase (MAB5280, Millipore Bioscience Research Reagents), anti-ERK 1/2 (V114A, Promega), antiAkt (9272, Cell Signaling Technology), anti-phospho-Akt (ser473) (4060, Cell Signaling Technology) were used at dilutions of 1:200, 1:1000, 1:50, $1: 1000,1: 5000,1: 1000$, and 1:1000, respectively, for immunoblotting. Detection was obtained with secondary antibodies from Santa Cruz Biotechnology and by enhanced chemiluminescence reaction (ECL Plus Western Blotting Detection System, RPN2133, GE Healthcare). Monoclonal anti-mNET (NET-05, MAb Technologies) (Matthies et al., 2009), anti-Rab1la (Lapierre et al., 2001), anti-Akt1 (2938, Cell Signaling Technology), anti-Akt2 (D-17, sc-7127, Santa Cruz Biotechnology), and anti-insulin R $\beta$ (C-19, sc-711, Santa Cruz Biotechnology) were used at dilutions of 1:500, 1:110, 1:400, 1:100, and 1:50 for immunocytochemistry. Fluorescent secondary antibodies included highly cross-absorbed anti-mouse, anti-goat, or anti-rabbit IgG (Invitrogen). Insulin from bovine pancreas (I6634), clozapine (C6305), NE, and streptozotocin (STZ) (S0130) were obtained from Sigma (I6634). Akt1/2, Akt1, and Akt2 inhibitors (Lindsley et al., 2005) were generously provided by Dr. C. Lindsley (Vanderbilt University, Nashville, TN).

Cell and slice surface protein biotinylation. Biotinylation experiments were performed on intact cells as described previously (Sung et al., 2003; Garcia et al., 2005; Dipace et al., 2007). Briefly, hNET cells were plated at a density of $1 \times 10^{6}$ cells/well in a six-well poly-(D-lysine)-coated plate. Cells were serum starved for $30 \mathrm{~min}$ to $1 \mathrm{~h}$ before treatment, and washed with cold PBS containing $\mathrm{Ca}^{2+} / \mathrm{Mg}^{2+}$. Then, cells were incubated with $1.0 \mathrm{mg} / \mathrm{ml}$ sulfosuccinimidyl-2-(biotinamido)ethyl-1,3-dithiopropionate (NHS-SS-biotin, Pierce/Thermo Scientific) for $30 \mathrm{~min}$, washed, quenched with $100 \mathrm{~mm}$ glycine, and extracted in lysis buffer (PBS Ca${ }^{2+} / \mathrm{Mg}^{2+}, 1 \%$ Triton 100-X, and 0.5 mM PMSF at $4^{\circ} \mathrm{C}$ ). Lysates were centrifuged, total fractions reserved, and supernatants incubated with immobilized streptavidin beads (Pierce/ThermoScientific) for $1 \mathrm{~h}$ at room temperature. Beads were washed three times in lysis buffer, and bound proteins eluted with $2 \times$ sample buffer containing 2-mercaptoethanol. Proteins were separated by SDS-PAGE and immunoblotted. For estimation of relative amounts of proteins, the exposed films of the immunoblots were scanned, and band intensities were measured with Scion Image (Scion). For brain slice preparation and biotinylation, all procedures were performed according to Vanderbilt University Institutional Animal Care and Use Committee-approved procedures. Brain slices were prepared from C57BL/6J 15- to 20-week-old male mice from Jackson Laboratories that were anesthetized with isoflurane and rapidly decapitated. After brain removal, the brain was chilled in oxygenated $4^{\circ} \mathrm{C}$ sucrose solution (sucrose $210 \mathrm{~mm} ; \mathrm{NaCl} 20 \mathrm{~mm} ; \mathrm{KCl} 2.5 \mathrm{~mm} ; \mathrm{MgCl}_{2} 1$ $\mathrm{mm} ; \mathrm{NaH}_{2} \mathrm{PO}_{4} \cdot \mathrm{H}_{2} \mathrm{O} 1.2 \mathrm{~mm}$ ), and then, while in sucrose solution, $300 \mu \mathrm{m}$ coronal slices were made using a vibratome. Slices were then collected in oxygenated artificial CSF (ACSF) ( $\mathrm{NaCl} 125 \mathrm{~mm}, \mathrm{KCl} 2.5 \mathrm{~mm}$, $\mathrm{NaH}_{2} \mathrm{PO}_{4} \cdot \mathrm{H}_{2} \mathrm{O} 1.2 \mathrm{~mm}, \mathrm{MgCl}_{2} 1 \mathrm{~mm}, \mathrm{CaCl}_{2} \cdot 2 \mathrm{H}_{2} \mathrm{O} 2 \mathrm{~mm}$ ). For in vitro drug treatments, slices were then allowed to recover for $1 \mathrm{~h}$ at $37^{\circ} \mathrm{C}$ in oxygenated ACSF and were then followed by drug treatment (i.e., insulin) and subsequent biotinylation. For in vivo treated animals (STZ or clozapine experiments), slices were immediately washed twice with oxygenated $4^{\circ} \mathrm{C}$ ACSF after collection and then incubated with $4^{\circ} \mathrm{C}$ ACSF solution containing 1 $\mathrm{mg} / \mathrm{ml}$ EZ-Link Sulfo-NHS-SS-Biotin (Pierce/Thermo Scientific) for 45 $\mathrm{min}$. After biotin incubation, the slices were rinsed twice quickly and for two 10 min washes in oxygenated $4^{\circ} \mathrm{C}$ ACSF. The reaction was quenched by washing twice for $20 \mathrm{~min}$ each with oxygenated $4^{\circ} \mathrm{C}$ ACSF containing glycine. After quenching, slices were frozen on dry ice, and the cortex was cut out and frozen at $-80^{\circ} \mathrm{C}$ until used. For each experiment, a minimum of four animals was used for the collection of slices per treatment group, and a single slice was used for each sample (represented in the text as "N"). Single slices were lysed in 1\% Triton buffer ( 25 mm HEPES, $150 \mathrm{~mm} \mathrm{NaCl,} 2 \mathrm{~mm}$ sodium orthovanadate, $2 \mathrm{~mm} \mathrm{NaF}$, plus a mixture of protease inhibitors). Lysates were then centrifuged at $17,000 \times g$ for $30 \mathrm{~min}$ at $4^{\circ} \mathrm{C}$. After isolation of supernatant, $0.1 \%$ Triton pulldown buffer ( 25 mm HEPES, $150 \mathrm{~mm} \mathrm{NaCl}$, $2 \mathrm{~mm}$ sodium orthovanadate, $2 \mathrm{~mm} \mathrm{NaF}$, plus a mixture of protease inhibitors) was added. Total protein was taken, and the samples were processed for protein concentration determination using a Bio-Rad protein assay and spectrometry at $595 \mathrm{~nm}$ Biotinylated proteins were then isolated using ImmunoPure-immobilized streptavidin beads (Pierce/Thermo Scientific) overnight at $4^{\circ} \mathrm{C}$ with agitation. Beads were washed three times with $0.1 \%$ Triton pulldown buffer, and biotinylated proteins were then eluted in $50 \mu \mathrm{l}$ of $2 \times$ SDS-PAGE sample loading buffer at $95^{\circ} \mathrm{C}$ and then at room temperature. Total slice lysates and the biotinylated (slice surface) fraction underwent immunodetection for NET, pAkt473, total Akt, $\mathrm{Na}^{+} / \mathrm{K}^{+}$ATPase, and tyrosine hydroxylase (TH), as described previously.

Immunostaining. SCGNs were either serum starved for $1 \mathrm{~h}$ (insulin treatment) or nonstarved (Akt inhibitor treatment) in DMEM:F12 and treated with vehicle, insulin, Akt1, or Akt2 inhibitor for 20 or $60 \mathrm{~min}$, respectively. Slices were obtained as previously described (Cell and slice surface protein biotinylation). Slices and neurons were subsequently fixed with $\mathrm{PBS} \mathrm{Ca}^{2+}$ / $\mathrm{Mg}^{2+} / 4 \%$ paraformaldehyde, washed three times with $\mathrm{PBS} \mathrm{Ca}^{2+} / \mathrm{Mg}^{2+}$, permeabilized, and blocked with $\mathrm{PBS} / 4 \%$ bovine serum albumin (BSA)/ $0.15 \%$ Tween-20, and immunostained with the appropriate antibody dissolved in PBS plus 4\% BSA and 0.05\% Tween-20. Primary antibodies were visualized with the appropriate covalently Alexa-labeled secondary antibody from Invitrogen. Immunofluorescence was imaged using a PerkinElmer UltraView confocal with a Nikon Eclipse 2000-U microscope equipped with a $60 \times$ lens with a numerical aperture (NA) of 1.49, or an Olympus FV 1000 using a $60 \times$ lens with NA of 1.45 (Vanderbilt University Medical Center Cell Imaging Shared Resource). Image processing was performed using ImageJ and Adobe Photoshop.

Analysis of NET internalization. The quantitation of NET intracellular accumulation was achieved using pixel intensity plots of a single confocal section along a line through the center of each bouton using ImageJ. The line intersects the brightest spot on one side of the widest portion of the bouton perimeter. The line was extended beyond the limits of the bouton to generate a background value, and then divided into 20 bins (bin 10 is approximately at the center of the bouton) for the pixels spanning the bouton. NET fluorescence intensity of each bin was normalized to the fluorescence intensity of the brightest spot on the bouton perimeter $(100 \%)$ and the mean \pm SEM pixel intensity of each bin plotted. 
A
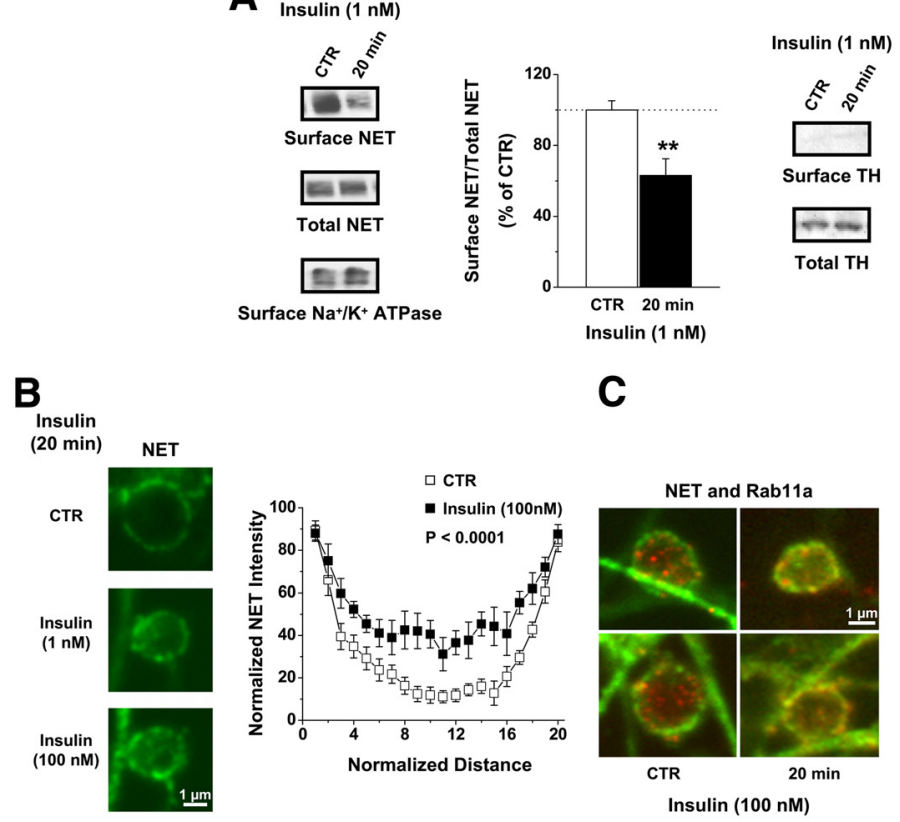

D
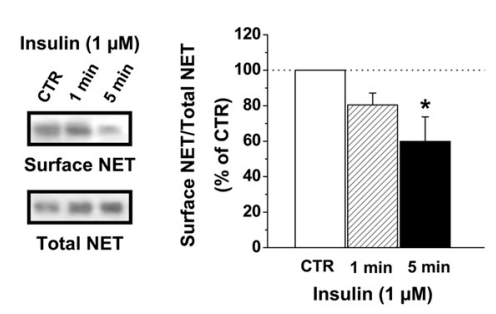
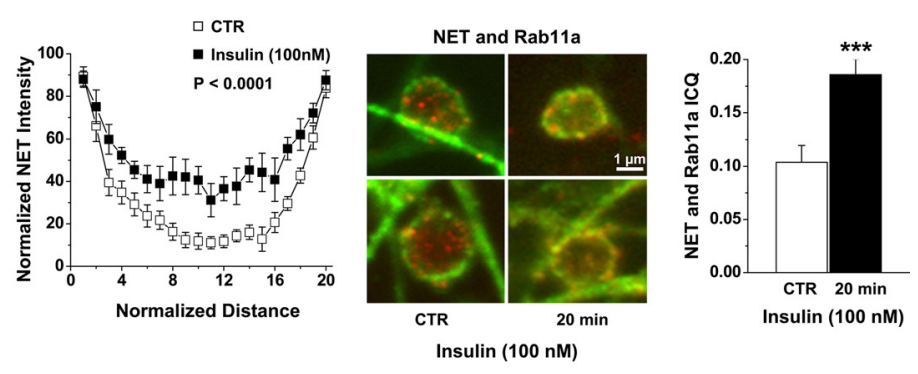

E

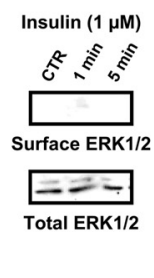

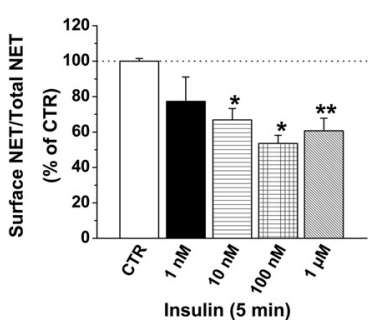

Figure 1. Insulin stimulation decreases NET surface levels in mouse hippocampal slices, SCGN boutons, and hNET cells. $A$, Left, Mouse hippocampal slices treated with either $1 \mathrm{~nm}$ insulin or vehicle (CTR) for $20 \mathrm{~min}$. Shown are representative Western blots of NET surface and total levels, as well as surface $\mathrm{Na}^{+} / \mathrm{K}^{+}$ATPase levels to serve as a loading control. Center, Quantification of the insulin-induced decrease in NET surface expression is also shown. Data are normalized to total NET and expressed as a percentage of control (mean \pm SEM, ${ }^{* *} p<0.01$, Student's $t$ test; $N=7-6$ ). Right, Representative Western blot of TH levels in the biotinylated and total fractions. $\boldsymbol{B}$, Left, Confocal images of NET distribution in SCGN boutons treated with vehicle (CTR), $1 \mathrm{~nm}$, or $100 \mathrm{~nm}$ insulin for $20 \mathrm{~min}$. Insulin treatments induce an increase in intracellular NET accumulation. Right, NET fluorescence intensity plots (see Materials and Methods) across SCGN boutons treated with vehicle (open squares) and $100 \mathrm{~nm}$ insulin (solid squares). The normalized NET intensity was plotted against the normalized distance, as described by Material and Methods (mean \pm SEM, $p<$ 0.0001 , two-way ANOVA; $N=18-8$ boutons). C, Left, Acute $100 \mathrm{~nm}$ insulin treatment for 20 min significantly increases NET and Rab11a colocalization in SCGN boutons with respect to vehicle (CTR). Right, Quantification of NET and Rab11a colocalization using the ICQ analysis (see Materials and Methods). Insulin significantly increases NET colocalization with the strictly intracellular protein Rab11a (mean $\pm S E M,{ }^{* * *} p<0.001$, Student's $t$ test; $N=23$ ). $\boldsymbol{D}$, Insulin decreases NET surface levels in a time-dependent manner in hNET cells. Left, Shown are representative Western blots for surface and total NET in cells treated with vehicle (CTR) or insulin at varying time points. Center, Western blot analysis showed that $1 \mu \mathrm{m}$ insulin exposure significantly decreases surface NET. Data are normalized to total NET and expressed as a percentage of control (mean $\pm S E M,{ }^{*} p<0.05$, one-way ANOVA followed by Dunnett's test; $N=4$ ). Right, The cytosolic extracellular signal-regulated kinases 1 and 2 (ERK1/2) are found in the total fraction but not in the surface fraction. $\boldsymbol{E}$, Quantitation of Western blots from hNET cells exposed to $5 \mathrm{~min}$ of insulin at varying concentrations (mean \pm SEM, ${ }^{*} p<0.05$ and ${ }^{* *} p<0.01$, one-way ANOVA followed by Dunnett's test; $N=3-8$ ).

Colocalization analysis. Only images in which there was no pixel saturation were analyzed. Background fluorescence was first subtracted in Image J by selecting an unstained area of each image and running the background subtraction plugin available at University Health Network research facilities (Toronto, ON, Canada). The intensity correlation quotient (ICQ) was then determined by running the intensity correlation analysis (ICA) plugin for ImageJ developed by Tony Collins and Elise Stanley (Toronto Western Research Institute, Toronto, ON, Canada), also available at the above link. The ICQ indicates whether the intensity of staining for two proteins varies in synchrony over space. An ICQ value of +0.5 means that in any pixel with a certain intensity of staining for one protein, the intensity of staining for the other protein studied will be exactly the same, whereas an ICQ value of 0 signifies no relation between the two staining patterns. Consistently, an ICQ value of -0.5 indicates an inverse relationship for colocalization. This method is based on the synchrony around which two signals vary in space (Li et al., 2004).

Uptake assay. hNET cells were seeded into six-well plates $24-48 \mathrm{~h}$ before the experiment and grown to confluency. After $30 \mathrm{~min}$ of serum starvation, the cells were incubated with $10 \mathrm{~nm}$ insulin for $1 \mathrm{~min}$ (Sigma) in KrebsRinger-HEPES (KRH)/glucose buffer at $37^{\circ} \mathrm{C}$. The cells were then placed into $37^{\circ} \mathrm{C} \mathrm{KRH/glu-}$ cose uptake buffer for $10 \mathrm{~min}(130 \mathrm{~mm} \mathrm{NaCl}$, $1.3 \mathrm{~mm} \mathrm{KCl}, 10 \mathrm{~mm}$ HEPES, $1.2 \mathrm{~mm} \mathrm{MgSO}_{4} 1.2$ $\mathrm{mm} \mathrm{KH} 2 \mathrm{PO}_{4}, 2.2 \mathrm{~mm} \mathrm{CaCl}, 10 \mathrm{~mm}$ glucose, $\mathrm{pH}$ 7.4) containing $100 \mu \mathrm{M}$ ascorbic acid, 100 $\mu \mathrm{m}$ pargyline, and $\left[{ }^{3} \mathrm{H}\right] \mathrm{DA}$ (dopamine) $(50$ $\mathrm{nM}$ ) for uptake; depending on the treatment group, the uptake buffer also had vehicle, 10 $\mathrm{nm}$ insulin, or cocaine to measure nonspecific uptake. Immediately after uptake, cells were washed in cold $4^{\circ} \mathrm{C} \mathrm{KRH/glucose} \mathrm{buffer} \mathrm{three}$ times. All solution was removed, and plates were allowed to dry on the $37^{\circ} \mathrm{C}$ plate. Once dry, cells were lysed with $1 \mathrm{ml}$ of $0.01 \%$ SDS. Radioactivity was measured in a Beckman scintillation counter with UniverSol mixture. Specific uptake was defined as total uptake minus nonspecific uptake in the presence of $10 \mu \mathrm{M}$ cocaine.

STZ treatment. All procedures were approved by the Vanderbilt University Medical Center and the University of Texas Health Science Center at San Antonio Institutional Animal Care and Use Committees and were conducted according to the National Institutes of Health Guide for the Care and Use of Laboratory Animals. For all experiments, male C57BL/6J 15- to 20-week-old mice from Jackson Laboratories served as experimental subjects. STZ is an antibiotic that destroys the insulin-secreting $\beta$ cells of the pancreas and has previously been used to induce chronic hypoinsulinemia in rats by our laboratories (Galici et al., 2003; Owens et al., 2005). STZ (Sigma-Aldrich) was freshly dissolved in ice-cold $100 \mathrm{~mm}$ citrate saline, $\mathrm{pH}$ 4.5, for all studies. Mice received STZ (200 $\mathrm{mg} / \mathrm{kg}$, i.p.) for biochemical and high-speed chronoamperometry (HSCA) studies and were returned to their home cages for 7-10 d. Weight and blood glucose were measured before injection and after injection. Blood glucose was measured with a glucometer (Advantage Accu-Chek, Roche Diagnostics) before STZ, at $48 \mathrm{~h}$ after injection, and at the time the animal was killed. Animals were considered hypoinsulinemic when their blood glucose levels exceeded 300 $\mathrm{mg} / \mathrm{dl}$.

Tissue extraction for neurochemistry. The brain sections were homogenized in 100-750 $\mu \mathrm{l}$ of $0.1 \mathrm{M}$ TCA, containing $10^{-2} \mathrm{M}$ sodium acetate, $10^{-4} \mathrm{M}$ EDTA, $5 \mathrm{ng} / \mathrm{ml}$ isoproterenol (as internal standard), and $10.5 \%$ methanol, pH 3.8. Samples were spun in a microcentrifuge at $10,000 \times g$ for $20 \mathrm{~min}$. The supernatant was removed and stored at $-80^{\circ}$. The pellet was saved for protein analysis. Supernatant was then thawed and spun for $20 \mathrm{~min}$. Samples of the supernatant were then analyzed for biogenic monoamines and/or amino acids. Biogenic amines were determined by a specific HPLC assay using an Antec Decade II (oxidation, $0.5 \mathrm{~V}$ ) electrochemical detector operated at $33^{\circ} \mathrm{C}$. Samples of the supernatant were 
injected using a Waters $717+$ autosampler, 20 onto a Phenomenex Nucleosil $(5 \mu \mathrm{m}, 100$ A) C18 HPLC column $(150 \times 4.60 \mathrm{~mm})$. Biogenic amines were eluted with a mobile phase consisting of $89.5 \% 0.1 \mathrm{M} \mathrm{TCA}$, $10^{-2} \mathrm{M}$ sodium acetate, $10^{-4} \mathrm{M}$ EDTA and $10.5 \%$ methanol, $\mathrm{pH} 3.8$. Solvent was delivered at $0.6 \mathrm{ml} / \mathrm{min}$ using a Waters 515 HPLC pump. Using this HPLC solvent, the following biogenic amines elute in the following order: noradrenaline, MHPG (3-methoxy-4-hydroxyphenylglycol), adrenaline, DOPAC, dopamine, 5-HIAA (5-hydroxyindoleacetic acid), homovanillic acid, 5-HT, and 3-methoxytyramine. HPLC control and data acquisition are managed by Millennium 32 software.

HSCA. HSCA is an electrochemical recording technique, which affords the kinetics of NE clearance to be measured in vivo. Detailed methods have been published previously (Daws et al., 2005; Toney and Daws, 2006). Mice were anesthetized by intraperitoneal injection $(2 \mathrm{ml} / \mathrm{kg}$ body weight $)$ of a mixture of chloralose $(25 \mathrm{mg} / \mathrm{kg})$ and urethane $(250 \mathrm{mg} / \mathrm{kg})$ followed by tracheal intubation and placement into a stereotaxic frame. Body temperature was maintained at $36-37^{\circ} \mathrm{C}$, and blood oxygen levels monitored (MouseOximeter, StarrLifeSciences) and maintained above $90 \%$. A Nafion-coated carbon fiber electrode was attached to a glass micropipette containing NE. The assembly was lowered into the brain region of interest [stereotaxic coordinates (in $\mathrm{mm}$ ): dentate gyrus region of hippocampus anteroposterior, -1.6 to -1.7 ; mediolateral, 0.5 ; dorsoventral, -1.8 to -2.0$]$; and NE pressure ejected to achieve concentrations at the recording electrode range, $\sim 0.2-4.0 \mu \mathrm{M}$. High-speed chronoamperometric recordings were made using the FAST-12 and FAST-16 systems (Quanteon). Oxidation potentials consisted of $100 \mathrm{~ms}$ pulses of $+0.55 \mathrm{~V}$. Each pulse was separated by a $900 \mathrm{~ms}$ interval during which the electrode potential was maintained at $0.0 \mathrm{~V}$. Voltage at the active electrode was applied with respect to an $\mathrm{Ag} / \mathrm{AgCl}$ reference electrode positioned in the extracellular fluid of the ipsilateral superficial cortex. Electrode placement was confirmed by making an electrolytic lesion at the recording site at the conclusion of the experiment.

Statistical analysis. All data are expressed as the mean \pm SEM. Mean differences between groups were determined using $t$ tests or one- and two-way ANOVAs followed by post hoc tests when the main effect or interaction was significant at $p<0.05$. Statistical analyses were conducted using software from Graph-Pad Prism. The number of animals and specific statistical analyses used in each experiment are indicated in the figure legends and/or text.

\section{Results}

Acute insulin treatment decreases NET surface levels in the central and peripheral nervous systems as well as in heterologous preparations

NET plays a pivotal role in controlling global noradrenergic tone, and its aberrant regulation has the capacity to impact mental health (Ganguly et al., 1986; Klimek et al., 1997; Rumantir et al., 2000; Shannon et al., 2000; Hahn et al., 2003, 2005, 2008, 2009; Kim et al., 2006; Haenisch et al., 2008). Evidence indicates that insulin signaling regulates NE homeostasis (Shimizu, 1991; Figlewicz et al., 1993, 1996; Barber et al., 2003). Thus, understanding how insulin/Akt fine tunes NET trafficking and/or function may provide an interesting and plausible link between metabolic dysfunction and mental disorders such as depression and schizophrenia (Mukherjee et al., 1989, 1996; Lustman and Clouse, 2005; Zhao et al., 2006). Our goal is to determine the nature of the regulation of NET by insulin in the CNS and peripheral nervous system. Here, we provide evidence for the role of insulin in the downregulation of the transporter from the surface. Utilizing a new assay, slice biotinylation, we show for the first time that acute in vitro treatment of mouse hippocampal slices with $1 \mathrm{nM}$ insulin significantly diminishes surface levels of NET (Fig. 1A). TH, a cytosolic protein, is detected primarily in the total fraction and comprises $<1 \%$ of the surface fraction. Therefore, these data demonstrate that the biotinylated fraction represents cell surface proteins and speaks to the health of noradrenergic TH-
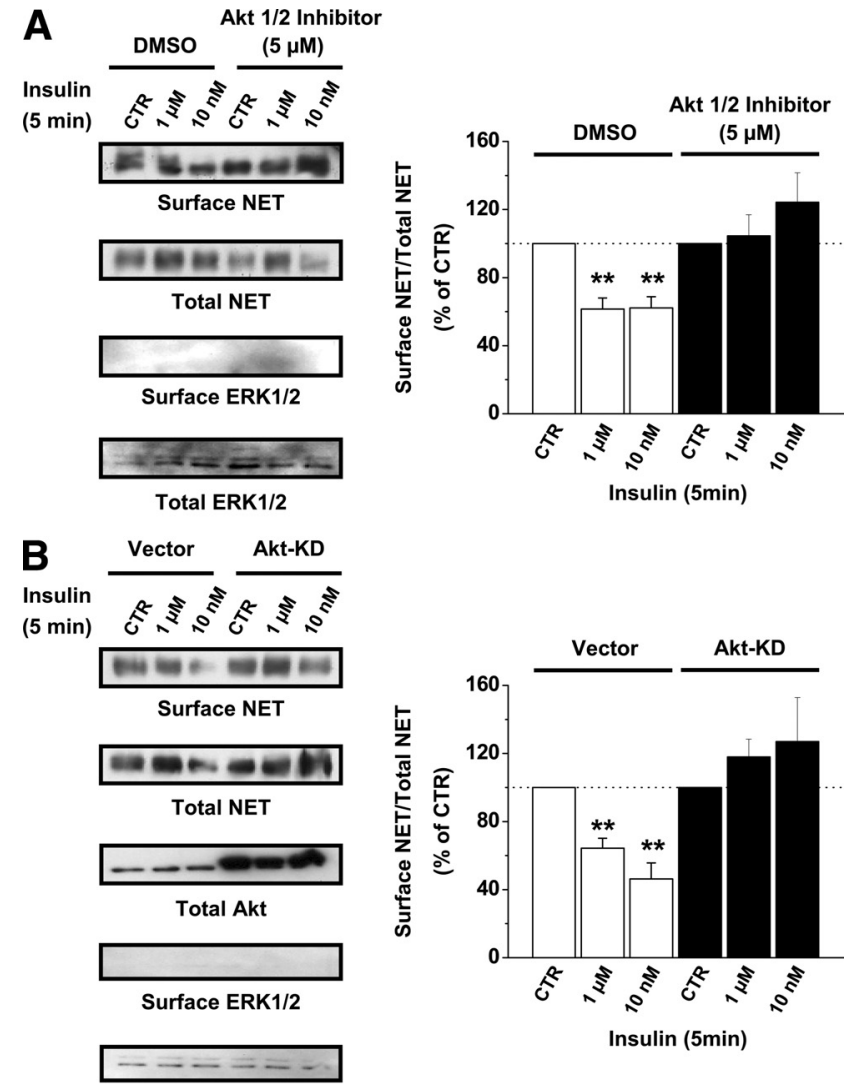

Total ERK1/2

Figure 2. In hNET cells, Akt inhibition and Akt-kinase dead (KD) overexpression prevents insulin-induced NET trafficking. $\boldsymbol{A}$, Left, Representative Western blot of NET from hNET cells incubated in medium containing $0.1 \%$ DMSO or the dual Akt $1 / 2$ inhibitor $(5 \mu \mathrm{m})$ dissolved in DMSO 30 min before and during either vehicle (CTR) or insulin treatment ( $5 \mathrm{~min}$ ). The absence of cytosolic extracellular signal-regulated kinase 1 and 2 (ERK1/2) bands in the biotinylated fraction supports the integrity of the biotinylation assay. Right, Quantitation of Western blots represented by the left panel. Data are normalized to total NET and expressed as a percentage of control (mean \pm SEM, ${ }^{* *} p<0.01$, one-way ANOVA followed by Dunnett's test; $N=4-5$ ). $\boldsymbol{B}$, $48 \mathrm{~h}$ before treatment with vehicle (CTR) or insulin $(5 \mathrm{~min})$, hNET cells are transfected with either Akt-KD, a kinase dead dominant negative form of Akt or pcDNA3.1 (vector). Left, A representative Western blot shows that overexpression of Akt-KD inhibits the insulin-induced reduction of surface NET compared with vector transfected control. Overexpression of Akt-KD was confirmed by probing for total levels of Akt. The cytosolic kinases ERK1/2 are found in the total fraction but not in the surface fraction. Right, Quantitation of multiple Western blots represented by the left panel. Surface NET is normalized to total NET levels and expressed as a percentage of control (mean $\pm \mathrm{SEM},{ }^{* *} p<0.01$, one-way ANOVA followed by Dunnett's test; $N=4-5)$.

positive neurons in the assay. These results provide a molecular mechanism to describe the decreased NE uptake described by Figlewicz et al. (1993). In addition to revealing a role for insulin in the regulation of NET trafficking in slices from the CNS, we also sought to demonstrate the ability of insulin to regulate NET in the peripheral nervous system.

SCGNs enable us to investigate the role of insulin in the peripheral nervous system. Importantly, due to the large diameter $(2-4 \mu \mathrm{m})$ of SCGN boutons, these cultures also provide us with the unique opportunity to study NET regulation at presynaptic sites of NE release (Matthies et al., 2009). Before exploring the role of insulin in the regulation of these noradrenergic neuronal cultures, we sought to demonstrate that these cells express the insulin receptor (IR). Not only is IR $\beta$ staining abundant throughout the SCGN (data not shown), the receptor is also specifically localized to single boutons (supplemental Fig. S1, avail- 
A
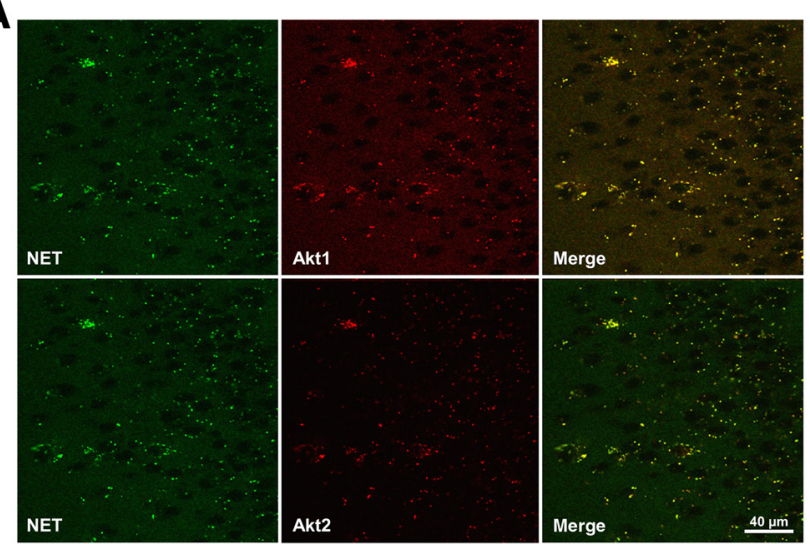

B
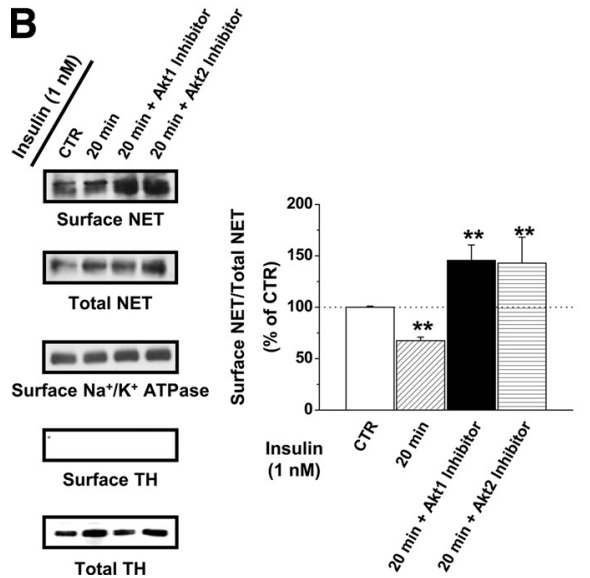

C
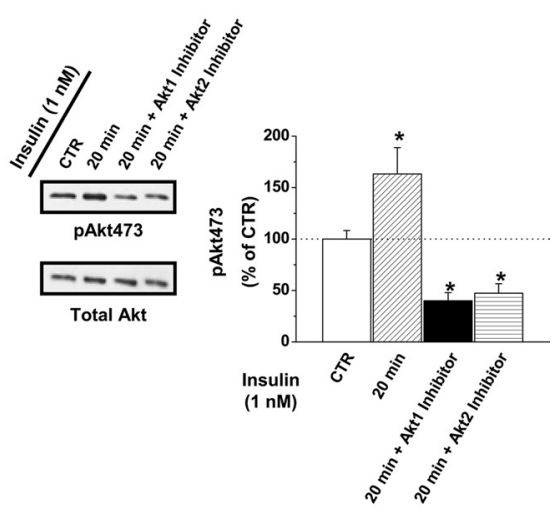

Figure 3. Akt1 and Akt2 colocalize with NET at terminals in mouse hippocampal slices, and their inhibition precludes insulinstimulated decreases in surface NET. $\boldsymbol{A}$, Confocal images of NET (green), Akt1 (red, top), and Akt2 (red, bottom) immunoreactivity in mouse hippocampal slices. The merge panels provide evidence of colocalization between NET and both isoforms of Akt. $\boldsymbol{B}$, Mouse hippocampal slices were treated with vehicle or the specific is oform inhibitor for Akt1 or Akt2 (12 $\mu \mathrm{m})$ for 40 min before and during $1 \mathrm{~nm}$ insulin treatment for $20 \mathrm{~min}$. Left, Shown is a representative Western blot of surface and total levels of NET, although surface $\mathrm{Na}^{+} / \mathrm{K}^{+}$ATPase levels serve as a loading control. TH is detected in the total fraction but absent in the surface fraction. Right, Quantification of multiple Western blots represented by the left panel. Surface NET is normalized to total NET and expressed as a percentage of control (mean $\pm \mathrm{SEM},{ }^{* *} p<0.01$, one-way ANOVA followed by Dunnett's test; $N=10-7$ ). C, Left, Representative Western blot from the same mouse hippocampal slice samples used for quantitation in $\boldsymbol{B}$ probed for phosphorylated Akt at serine residue 473 (pAkt473) and total levels of Akt. Right, Quantification of pAkt473 levels in slices treated as in $\boldsymbol{B}$. pAkt473 levels are expressed as a percentage of control (mean \pm SEM, ${ }^{*} p<0.05$, one-way ANOVA followed by Dunnett's test; $N=8-9$ ).

able at www.jneurosci.org as supplemental material). After demonstrating the presence of IRs on noradrenergic SCGNs, we serum starved the SCGN cultures for $1 \mathrm{~h}$, and then treated them with vehicle, $1 \mathrm{nM}$, or $100 \mathrm{~nm}$ insulin for $20 \mathrm{~min}$ and discovered a dramatic increase in intrabouton NET immunoreactivity (Fig. $1 B)$. We quantified these observations using pixel intensity plots of a single confocal section (see Materials and Methods). Pixel intensity plots were obtained from a straight line drawn across the widest region of the approximately spherical bouton, starting at the brightest spot of fluorescence on one side of the bouton. The subsequent line spanned the entire diameter of the bouton and was extended beyond the limits of the bouton to provide a background value. This line was then divided arbitrarily into 20 bins, and the NET fluorescence intensity of each bin was normalized to the fluorescence intensity of the brightest spot on the perimeter of the bouton $(100 \%)$. The mean \pm SEM pixel intensity (normalized NET intensity) is plotted against each bin (normalized distance). Figure $1 B$ shows that in insulin-treated neurons, the NET intrabouton fluorescence signal is significantly higher than in vehicle-treated neurons, as shown by a shift in the curve upward.
This demonstrates that NET is accumulated intracellularly upon $100 \mathrm{~nm}$ insulin treatment. Our result that $100 \mathrm{~nm}$ insulin treatment significantly increases intracellular NET accumulation is further substantiated by costaining for the recycling endosome marker Rab11a. Rab11a is a GTPase that plays an important role in the trafficking of numerous proteins including NET via "slow" recycling endosomes (Matthies et al., 2010). Importantly, we show that $100 \mathrm{~nm}$ insulin exposure significantly enhances NET colocalization with the strictly intracellular protein Rab11a (Fig. 1C). This increase in colocalization was quantified by using the ICA/ICQ method (Li et al., 2004). We calculated the ICQ of NET and Rab1 la in boutons, and found a significant increase upon $100 \mathrm{~nm}$ insulin treatment (Fig. 1C).

Our results, for the first time, demonstrate the ability of insulin to induce NET trafficking, in both the CNS and peripheral nervous system. Furthermore, this regulation is seen not only at the level of hippocampal slices but also at the level of a single bouton. To dissect this insulininduced regulation further, we chose to study it in a more malleable system, Chinese hamster ovary $(\mathrm{CHO})$ cells with stably transfected HA-tagged human hNET cells. Here, we validate this model by demonstrating that insulin-induced trafficking of NET away from the cell surface is both time and dose dependent in hNET cells. Incubation of hNET cells for $5 \mathrm{~min}$ with $1 \mu \mathrm{M}$ insulin results in a significant reduction of NET in the biotinylated fraction (Fig. 1D). Additionally, 5 min of insulin exposure at varying doses results in significant decreases in surface NET (Fig. $1 E)$. In addition, to the ability of insulin to modulate NET surface availability in these cells, uptake assays also support an insulin-mediated decrease in NET function. Consistent with previous results, our data reveal a significant decrease in $\left[{ }^{3} \mathrm{H}\right]$ DA uptake after exposure to $10 \mathrm{~nm}$ insulin (vehicle, $1.162 \pm 0.020$ pmol $^{\star}$ well $^{-1 \star}$ min $^{-1}$; insulin, $0.986 \pm 0.020$ pmol $^{\star}$ well $^{-1 \star} \mathrm{min}^{-1}$; mean \pm SEM, ${ }^{* *} p<0.01$ by Student's $t$ test; $N=4^{-3}$ ). The time- and dose-dependent changes in NET surface levels and function in response to insulin in hNET cells illustrates the utility of this system for studying the intricacies of regulation of this transporter by insulin. In particular, we sought to uncover specifically which components of the insulin-signaling pathway are essential for insulin-induced NET regulation.

\section{Insulin requires Akt to induce changes in NET surface expression}

Insulin receptors are tyrosine kinase receptors which upon activation result in the recruitment of both phosphatidylinositol 3-kinase (PI3K) and Akt to the membrane for subsequent activation. Akt, in particular, is a multifunctional kinase that is involved with diverse pathways in, for example, cell growth, survival, and 
metabolism. Indeed, aberrant Akt function has been implicated in a vast array of disorders such as diabetes, obesity, cancer, autoimmune disease, as well as mental disorders such as depression and schizophrenia (Hsiung et al., 2003; Emamian et al., 2004; Dummler and Hemmings, 2007; Karege et al., 2007; Manning and Cantley, 2007; Krishnan et al., 2008). Although genetic evidence for the involvement of Akt in mental disorders grows, how Akt dysregulation impacts these diseases at the molecular level is still unclear. Importantly, it has been shown that Akt is critical for the regulation of other transporters such as the glucose and dopamine transporter by insulin (Carvelli et al., 2002; Garcia et al., 2005; He et al., 2007; Zaid et al., 2008). Here, we investigate whether Akt plays a critical role in the insulin regulation of NET by using the isoform specific Akt1, Akt2, or Akt1/2 inhibitors (DeFeo-Jones et al., 2005; Lindsley et al., 2005; She et al., 2008). These inhibitors are allosteric inhibitors that require the pleckstrin homology $(\mathrm{PH})$ domain of Akt to inhibit phosphorylation and activation of the kinase. Although they require this domain for inhibition, binding of the inhibitors to Akt requires the whole protein since in vitro assays show the PH domain alone is insufficient for binding. Furthermore, the inhibitors reversibly inhibit both the activation and activity of Akt and are highly specific for Akt compared with other similar kinases such as protein kinase A, protein kinase $\mathrm{C}$, and serum-/glucocorticoid-regulated kinase. In our studies, $5 \mu \mathrm{M}$ application of the dual Akt1/2 inhibitor to hNET cells $30 \mathrm{~min}$ before and during insulin exposure prevents insulin-stimulated trafficking of NET away from the surface (Fig. $2 \mathrm{~A}$ ). In addition to pharmacological blockade, we also use a "kinase-dead" dominant-negative mutant (K179R) construct of Akt (Akt-KD) to show that Akt activity is required for insulin-induced regulation of the transporter (Garcia et al., 2005). Consistent with our previous results, transient transfection of hNET cells with the Akt-KD construct $48 \mathrm{~h}$ before insulin application abolishes insulin-stimulated trafficking of NET away from the plasma membrane (Fig. $2 B$ ). Although both genetic and pharmacological inhibition of Akt prevents insulin-induced regulation of the transporter in hNET cells, we sought to extend these observations to a more physiologically system.

Given the abundance of NET expression in mouse hippocampal slices, we chose this experimental system to investigate the role of Akt in the insulin regulation of NET. Although all three isoforms of Akt are expressed within the brain, the distribution and differences in their expression across various regions of the brain are relatively uncharacterized (Easton et al., 2005). We anticipate that for Akt to regulate the transporter it should be localized in the same neuronal domain. Indeed, NET, Akt1, and Akt2 costaining of slices reveals that Akt1 and Akt2 are heavily expressed in NET-positive hippocampal terminals (Fig. 3A). Thus, Akt is poised for regulating the transporter in hippocampal slices. Consistent with these findings, insulin-stimulated decreases in NET are abolished by pretreatment with either the Akt1 or Akt2 inhibitor for $1 \mathrm{~h}$ before and during insulin exposure (Fig. 3B). These data demonstrate that insulin-induced downregulation of NET requires Akt activity. Interestingly, changes in the phosphorylation status of Akt at serine residue 473, which relates to Akt activation, correlate well with changes in NET surface levels (Fig. 3C). This correlation is seen consistently throughout our studies and led us to hypothesize that Akt alone, which can be stimulated by numerous pathways, is a pivotal regulator of the transporter. Before investigating the effects of alter-
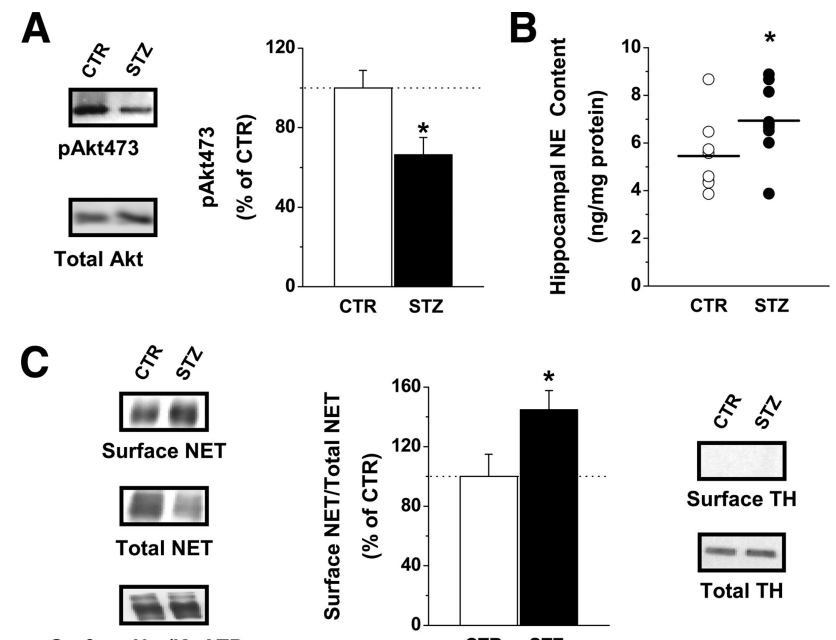

Surface $\mathrm{Na}^{+} / \mathrm{K}^{+}$ATPase
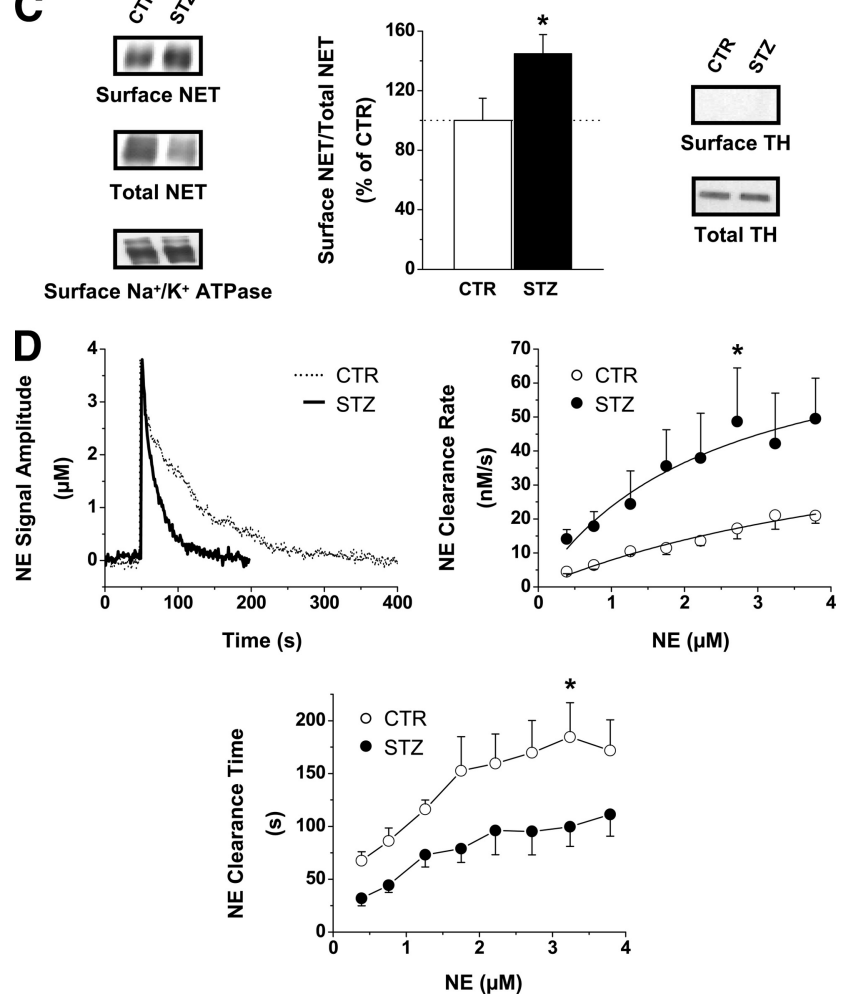

Figure 4. STZ-induced hypoinsulinemia decreases hippocampal Akt phosphorylation while significantly increasing NET surface expression and function. Mice were injected with either vehicle (CTR) or $200 \mathrm{mg} / \mathrm{kg}$, i.p., STZ to mimic a type I diabetic state, as described in Materials and Methods. $A$, Left, Representative Western blot of pAkt473 and total Akt levels in mouse hippocampal slices from CTR or STZ mice. Right, Quantitation of pAkt473 levels from CTR and STZ mouse hippocampal slices. Data are represented as percentage of CTR (mean $\pm S E M,{ }^{*} p<$ 0.05 , Student's $t$ test; $n=14-11)$. $B$, Tissue content of norepinephrine as measured by HPLC from hippocampal homogenates in CTR versus STZ mice (mean \pm SEM, ${ }^{*} p<0.05$, Student's $t$ test; $N=9-8$ ). , Left, Shown is a representative Western blot of surface and total levels of NET from hippocampal slices of either CTR or STZ mice. Surface $\mathrm{Na}^{+} / \mathrm{K}^{+}$ATPase levels serve as a loading control. Center, Quantitation of Western blots represented by the left panel. Surface NET is normalized to total levels of NET and expressed as a percentage of CTR (mean \pm SEM, ${ }^{*} p<$ 0.05 , Student's $t$ test; $N=14-11$ ). (Right) The absence of cytosolic TH bands in the biotinylated fraction supports the integrity of the hippocampal slice biotinylation assay. D, Left, Oxidation currents (converted to micromolar concentration using a calibration factor determined in vitro) produced by pressure ejection of $0.8-60 \mathrm{pmol}$ of NE into the dentate gyrus region of the hippocampus of anesthetized CTR and STZ mice. Corresponding summary data for the rates ( $\mathrm{nmol} / \mathrm{s}$ ) (right) and time (in seconds) (bottom) of NE clearance plotted as a function of increasing concentrations of NE (CTR, $n=8 ; \mathrm{STZ}, n=7$; rate: main effect treatment, $p=0.0453$; main effect NE concentration, $p<0.0001$; time: main effect treatment, $p=$ 0.0255 ; main effect NE concentration, $p<0.0001$, two-way ANOVA with Bonferroni post hoc comparisons, ${ }^{*} p<0.05$ ).

ing Akt activity independent of insulin signaling, however, we sought to determine whether in vivo manipulation of insulin and Akt signaling results in significant changes in NET regulation and consequential monoamine homeostasis. 
A
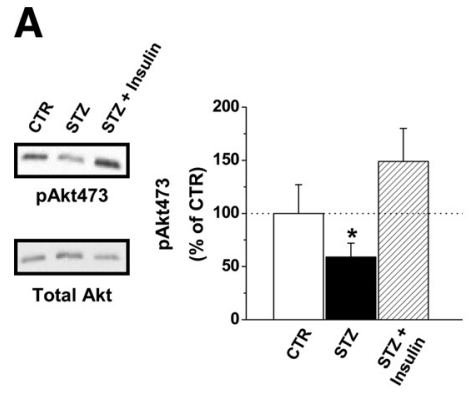

B
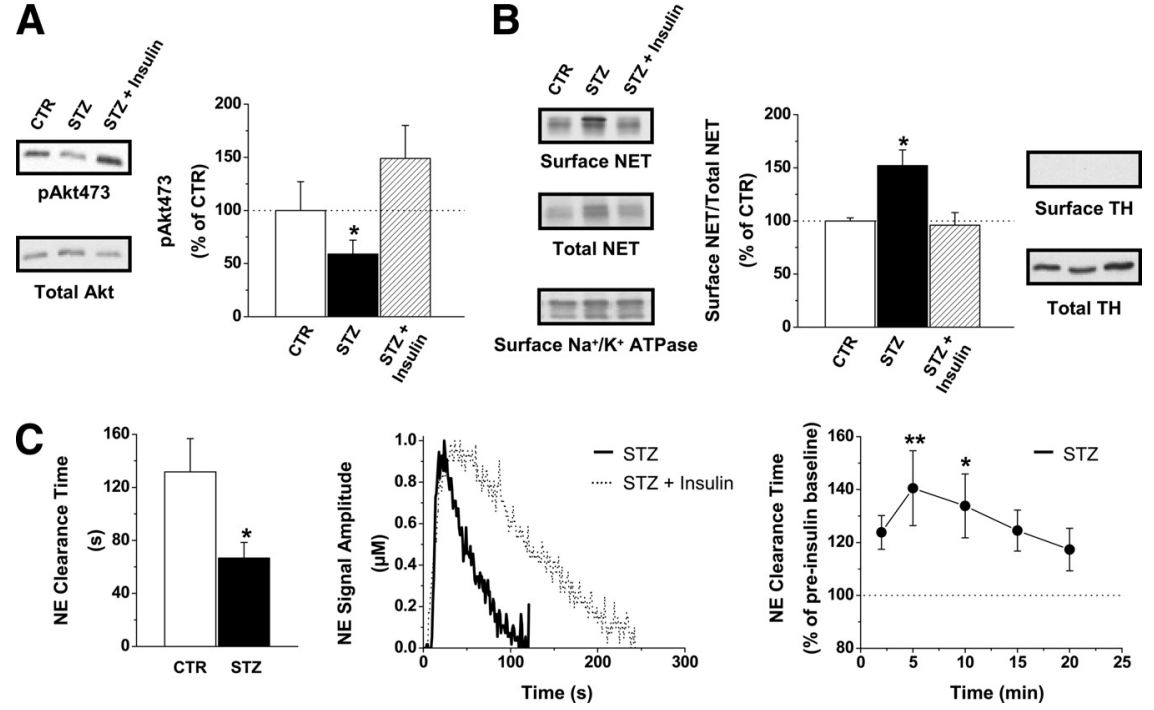

Figure 5. Acute insulin treatment in vitro and in vivo restores Akt deficits, NET surface expression, and function in the hippocampus of STZ-treated mice. Mice were injected with either vehicle (CTR) or $200 \mathrm{mg} / \mathrm{kg}$, i.p., STZ to mimic a type I diabetic state, as described in Materials and Methods. A, Left, Representative Western blot of pAkt473 and total Akt levels in hippocampal slices from control mice (CTR) or STZ mice. Slices from STZ mice were then subdivided and treated either with $1 \mathrm{~nm}$ insulin for $20 \mathrm{~min}$ (STZ + Insulin) or with vehicle (STZ). Right, Quantitation of pAkt473 levels from CTR, STZ, or STZ + Insulin mouse hippocampal slices. Data are represented as percentage of CTR (mean \pm SEM, ${ }^{*} p<0.05$, one-way ANOVA followed by Dunnett's test; $n=9$ ). $\boldsymbol{B}$, Left, Shown is a representative Western blot of surface and total levels of NET from hippocampal slices of either CTR or STZ mice, with slices from STZ mice subdivided and treated either with $1 \mathrm{~nm}$ insulin for $20 \mathrm{~min}$ (STZ + Insulin) or with vehicle (STZ). Surface $\mathrm{Na}^{+} / \mathrm{K}^{+}$ATPase levels serve as a loading control. Center, Quantitation of Western blots represented by the left panel. Surface NET is normalized to total levels of NET and expressed as percentage of CTR (mean $\pm S E M,{ }^{*} p<0.05$, one-way ANOVA followed by Dunnett's test; $n=8$ ). Right, The absence of cytosolic TH bands in the biotinylated fraction supports the integrity of the hippocampal slice biotinylation assay. C, Left, Summary data from HCSA experiments comparing clearance time of exogenous NE in the dentate gyrus of STZ treated versus saline treated control mice (see Fig. $4 D$ and Materials and Methods for details; mean \pm SEM, ${ }^{*} p<0.05$, Student's $t$ test; $n=6$ ). Local application of exogenous NE to the dentate gyrus of anesthetized mice was used to produce signal amplitudes of $\sim 1 \mu \mathrm{m}$. After three reproducible NE signals were obtained, exogenous insulin (10 $\mu \mathrm{m} / 100 \mathrm{nl}$ to deliver $1 \mathrm{pmol}$ ) was locally applied to the dentate gyrus, and 2 min later NE was applied again, and then at 5 min intervals, until the NE signal returned to its pre-insulin baseline. Center, Representative oxidation currents (converted to micromolar m concentration using a calibration factor determined in vitro) produced by pressure ejection of $1 \mathrm{pmol}$ of NE into the dentate gyrus region of the hippocampus of anesthetized STZ mice before (STZ) and 5 min after insulin (STZ + Insulin) application. Right, Average NE clearance time in STZ-treated mice after acute pressure injection of insulin. Data are expressed as a percentage of pre-insulin (baseline) clearance time. Insulin significantly increased NE clearance time in STZ-treated mice (mean \pm SEM, ${ }^{*} p<0.05$ and ${ }^{* *} p<0.01$, Friedman test followed by Dunn's multiple comparison test on data pictured. Identical results were obtained by one-way ANOVA followed, Dunnett's test on raw data; $n=6$ ).

\section{Hypoinsulinemic mice have reduced Akt phosphorylation, enhanced NE levels, and elevated NET surface expression/function}

To induce a hypoinsulinemic state, mice were injected with STZ, a selectively toxic compound targeting the insulin producing pancreatic $\beta$ cells (Lenzen, 2008). Original studies on STZinjected mice demonstrate that these mice display hallmarks of hypoinsulinemia such as aberrant glucose regulation, hyperphagia, and polyuria (Hernandez and Briese, 1972; Bell and Hye, 1983). In our studies, mice received one $200 \mathrm{mg} / \mathrm{kg}$, i.p., injection of STZ, and $48 \mathrm{~h}$ later blood glucose levels were measured to confirm drug efficacy. Control mice, which received vehicle injections, maintained normal glucose levels, whereas STZ-injected mice showed aberrantly elevated levels of blood glucose (supplemental Fig. S2, available at www.jneurosci.org as supplemental material). After measurement of blood glucose levels, mice were left untreated in the STZ-induced diabetic state for 7-10 d and were then killed for biochemical studies. STZ mice display deficits in Akt phosphorylation at ser473 in the hippocampus, which is accompanied by an increase in NE tissue content in the region (Fig. $4 A, B$ ). Importantly, studies show that appropriate NET function is critical for regulating NE tissue content (Xu et al., 2000). Thus, given the deficits in Akt phosphorylation and the significant elevation of NE tissue content, we hypothesize that these mice will display significantly enhanced NET levels. Moreover, evidence from previous studies shows that STZ rats have elevated steady-state levels of NET mRNA in the locus coeruleus (Figlewicz et al., 1996). Importantly, hippocampal slice biotinylation reveals a significant increase in surface NET in mice with STZ-induced hypoinsulinemia (Fig. 4C). To determine whether enhanced surface expression of NET in hippocampal slice preparations from STZ-treated mice results in increased NE clearance in hippocampus in vivo, we used HSCA. Clearance rate of NE locally injected into the dentate gyrus was significantly increased in STZ-treated mice, as indicated by the decreased time required for the NE signal to diminish in STZ mice compared with saline-treated mice (Fig. 4D, left panel). Consistently, the average clearance rate of NE over a range of concentrations, measured as described in Material and Methods, was significantly enhanced in STZ mice compared with control animals, such that the apparent maximal velocity for NE clearance was increased approximately twofold compared with control mice (Fig. 4D, right panel). Similarly, the average time required for NE clearance (NE clearance time) over the same range of concentrations was significantly reduced in STZ-treated mice (Fig. $4 D$, bottom). Thus, STZ mice display aberrant Akt regulation and increased NE tissue content in the hippocampus, which corresponds with increased NET surface expression and function. Importantly, the STZ-induced diabetic mice display normal protein levels of other noradrenergic markers in the hippocampus such as $\mathrm{TH}$ [control (CTR): $N=9,100.0 \pm 5.5 ;$ STZ: $N=11,94.5 \pm 7.2$; unpaired $t$ test, $p=0.57$ ] and dopamine $\beta$ hydroxylase (CTR: $N=7$, $100.0 \pm 8.5$; STZ: $N=9,101.7 \pm 8.2$; unpaired $t$ test, $p=0.89$ ). These data indicate that changes in NE tissue content correlates with altered NET surface expression and function, and are not due to changes in NE synthesis. In addition, to support our hypothesis that hypoinsulinemia induced by STZ underlies the alterations observed in NET expression and function, we sought to reverse these deficits in vitro and in vivo with acute insulin treatment. Again, STZ-treated mice had significantly reduced levels of Akt ser473 phosphorylation (Fig. 5A) and enhanced surface expression of NET (Fig. 5B) in biotinylated hippocampal slices relative to control mice. However, $1 \mathrm{~nm}$ insulin treatment for $20 \mathrm{~min}$ restores Akt phosphorylation levels and surface expression of the transporter to control levels (Fig. $5 A, B$ ). Thus, acute in vitro insulin treatment is sufficient to rectify STZ-induced alterations in hippocampal preparations. To determine whether a similar rescue is possible in vivo, we again used HSCA. As before, the average time required for NE clearance was significantly reduced, 
indicating enhanced NET function, in STZ-treated, hypoinsulinemic mice, relative to saline-treated control mice (Fig. $5 C$, left). Similar to our in vitro paradigm, local infusion of insulin $(10 \mu \mathrm{M} / 100 \mathrm{~nL}$ to deliver 1 pmol) was then used in the dentate gyrus of STZ mice in an attempt to rectify the changes observed in NET function. First, exogenous NE was locally applied $(200 \mu \mathrm{M} / 10 \mathrm{nl}$ to deliver $2 \mathrm{pmol})$ to achieve reproducible signals with amplitudes recorded at the carbon fiber electrode in the range of $1 \mu \mathrm{M}$. Insulin was then infused, and 2 min later NE was applied again. Importantly, insulin itself did not produce any electrochemical signal. Exogenous insulin application 5 min before NE infusion, however, significantly increased the time required for NE to clear from the extracellular fluid in the dentate gyrus, thus implying a significant reduction in NET function (Fig. $5 C$, center and right). The ability of in vitro and in vivo insulin application to restore STZ-induced deficits further supports the notion that peripheral hypoinsulinemia underlies NET dysfunction in these mice. Thus, our data from biotinylated hippocampal slices and in vivo HSCA in STZ-induced diabetic mice show for the first time that in vivo manipulation of insulin levels in the periphery impacts both Akt signaling/phosphorylation and NET function in the brain with consequences for monoamine homeostasis.

\section{Akt signaling regulates NET surface availability in hNET cells, SCGNs, and cortical slices after in vivo antipsychotic treatment}

We hypothesize that manipulation of Akt signaling either by pharmacological means or receptor stimulation, independently of insulin, alters the surface availability of NET. To investigate whether Akt signaling is capable of regulating NET trafficking, we exposed hNET cells to the Akt1/2 inhibitor $(5 \mu \mathrm{M})$ for varying time periods (Fig. 6A). Inhibition of Akt significantly increased NET surface expression in a time-dependent manner. Importantly, this pharmacological manipulation of Akt is independent of insulin status. To determine whether Akt regulates NET at sites of NE release, we extended these studies to boutons of SCGN cultures. Costaining of SCGN cultures for NET, Akt1, and Akt2 indicates that Akt is indeed present in the bouton and poised for regulation of the transporter (supplemental Fig. S3, available at www.jneurosci. org as supplemental material). Given the close proximity of both Akt isoforms to NET in the SCGN boutons, we exposed SCGN cultures to vehicle, Akt1 inhibitor, or Akt2 inhibitor for $1 \mathrm{~h}$ to determine whether both isoforms are capable of driving NET to the surface. To allow for Akt signaling inhibition by the Akt inhibitors, the neurons were not serum starved. Here we show, at
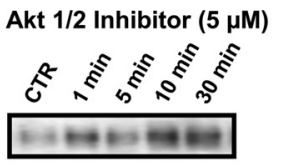

Surface NET

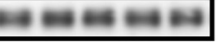

Total NET
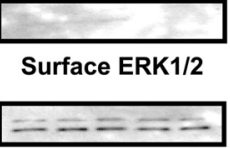

Total ERK1/2

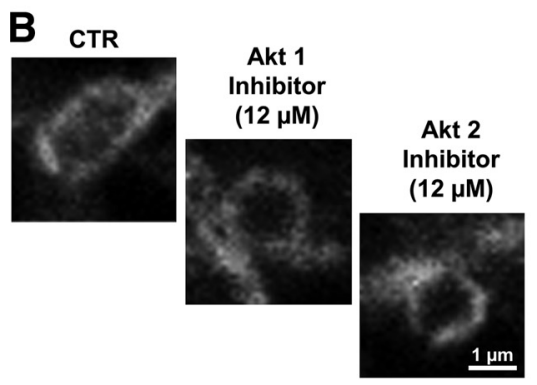

Akt 1/2 Inhibitor (5 $\mu \mathrm{M})$
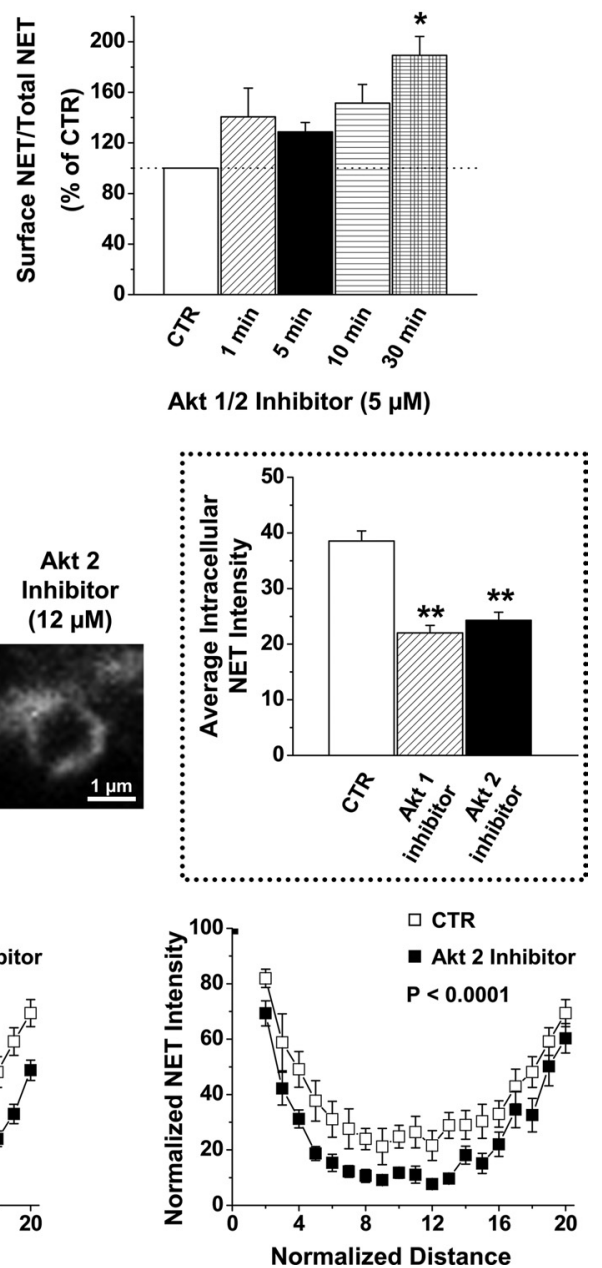

Figure 6. Basal Akt inhibition significantly increases NET surface expression. $\boldsymbol{A}$, hNET cells are treated with vehicle (CTR) or the dual Akt1/2 inhibitor (5 $\mu \mathrm{m}$ ) for varying amounts of time. Left, Shown is a representative Western blot of surface and total levels of NET after vehicle or Akt1/2 inhibitor treatment. Cytosolic ERK1/2 bands are not present in the surface fraction. Right, Quantitation of the increase in NET surface expression induced by Akt inhibition is also shown. Surface NET is normalized to total levels of NET Scultured and processed for immunocytochemistry, as described in Material and Methods. Top left, Confocal images of NET immunoreactivity in SCGN cultures treated with vehicle or either $12 \mu \mathrm{M}$ Akt1 or Akt2 inhibitor for $1 \mathrm{~h}$. Bottom, Analysis of intensity plots spanning SCGN boutons. The normalized NET intensity is plotted against the normalized distance, as described in $3-18$, which represent bins that are within the interior of the bouton, in CTR, Akt1 inhibition, or Akt2 inhibition conditions (mean \pm SEM, ${ }^{* *} p<0.01$, one-way ANOVA followed by Dunnett's test; $n=14$ ).

sites of synaptic NE release, that incubation of cultures with either the Akt1 or Akt2 isoform-specific inhibitors results in a significant increase in NET immunoreactivity on the perimeter of the bouton (Fig. $6 \mathrm{~B}$ ). Thus, both Akt1 and Akt2 are capable of regulating NET surface availability in SCGN. Again, we quantified these observations using pixel intensity plots of a single confocal section (see Materials and Methods). Upon Akt inhibition, the pixel intensity plots reveal a significant downward shift, indicating an increase in NET surface levels in response to Akt inhibition. Furthermore, the average NET intensity across inner bins (bins 3-17) reveals a significant decrease in NET immunoreactivity within the bouton in the presence of either Akt inhibitor (Fig. $6 B$, inset). These data demonstrate, for the first time, that Akt activity is a potent regulator of NET. 
A
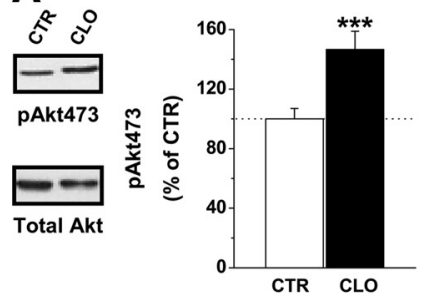

B
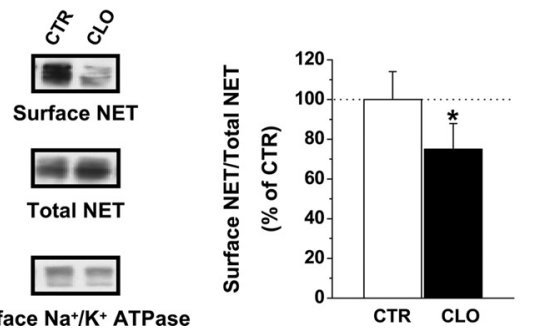

Figure 7. In vivo treatment with clozapine, an atypical antipsychotic, activates Akt and significantly reduces NET surface levels in mouse cortical slices. A, Mice are injected in vivo with either vehicle (CTR) or clozapine (CL0) $(10 \mathrm{mg} / \mathrm{kg}$, i.p., for $1 \mathrm{~h})$. Left, Representative Western blot of pAkt473 and total Akt levels from cortical slices of either CTR or CLO mice. Right, Quantification of pAkt473 levels from cortical slices of multiple animals (mean \pm SEM, ${ }^{* * *} p<0.001$, Student's $t$ test; $n=21$ ). $\boldsymbol{B}$, After in vivo clozapine injection and cortical slice preparation, slices are immediately biotinylated. Left, Shown is a representative Western blot of NET surface and total levels from CTR and CLO mice. Surface $\mathrm{Na}^{+} / \mathrm{K}^{+}$ATPase levels serve as a loading control. Center, A quantification of NET surface levels normalized to total NET levels and represented as percentage of control (mean \pm SEM, ${ }^{*} p<$ 0.05 , Student's $t$ test; $n=21$ ). Right, Cytosolic TH is absent in the biotinylated fraction.

Next, we determined whether activation of Akt by signaling pathways distinct from insulin are capable of altering NET surface expression. Numerous studies have shown that antipsychotics, such as clozapine, influence the phosphorylation status and activity of Akt in the cortex (Emamian et al., 2004; Kang et al., 2004; Roh et al., 2007). Our evidence suggests that alterations in the phosphorylation status of Akt correlate well with changes in NET surface expression. Thus, we determined whether in vivo intraperitoneal injections of clozapine are capable of altering both the phosphorylation state of Akt at ser473 as well as surface levels of NET. Mice received single $30 \mathrm{mg} / \mathrm{kg}$ i.p. injections of clozapine, and $1 \mathrm{~h}$ after injection the mice were killed and cortical slices were taken and biotinylated to examine both Akt phosphorylation and surface levels of NET. As expected, clozapine treatment significantly enhanced phosphorylation of Akt at ser473 in the cortex, whereas total levels remained unaltered (Fig. $7 A$ ). Importantly, this increase in Akt phosphorylation is accompanied by a significant decrease in the levels of surface NET (Fig. $7 B$ ). Thus, activation of Akt through receptor signaling distinct from that of insulin alters the dynamics of NET surface expression.

\section{Discussion}

Through its reuptake of synaptic NE and other monoamines such as DA, NET is pivotal for maintaining the integrity of monoaminergic signaling in the brain and periphery (Iversen, 1971; Pacholczyk et al., 1991; Xu et al., 2000; Moron et al., 2002). NET function is intricately controlled not only through regulation of transporter activity but also through the dynamic trafficking of the transporter to and from the plasma membrane (Apparsundaram et al., 1998a, 2001; Sung et al., 2003; Wersinger et al., 2006; Dipace et al., 2007). Importantly, single-nucleotide polymorphisms (SNPs) in NET that impact surface availability have been shown to be directly linked to both CNS and peripheral nervous system disorders, such as depression, attention deficit hyperactivity disorder (ADHD), orthostatic intolerance, and blood pressure abnormalities (Halushka et al., 1999; Hahn et al., 2003, 2005, 2009; Haenisch et al., 2008). Thus, the ability of abnormal NET surface expression to impact mental health and autonomic function makes it imperative that we understand how dysregulation of signaling pathways linked to these disorders impacts NET function. Notably, aberrant Akt signaling has been implicated in diseases such as diabetes and obesity, which have a high comorbidity with monoamine-related mental disorders, as well as with the pathology of schizophrenia and depression (Mukherjee et al., 1989, 1996; Hsiung et al., 2003; Emamian et al., 2004; Lustman and Clouse,

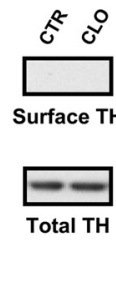

2005; Zhao et al., 2006; Karege et al., 2007; Krishnan et al., 2008). Here, our goal was to characterize how changes in Akt signaling regulate NET function in the nervous system.

We demonstrate, for the first time, that insulin and Akt signaling are capable of fine tuning NET surface levels and function in both the CNS and peripheral nervous system. We show that acute insulin treatment significantly decreases NET surface availability in mouse hippocampal slices, at sites of synaptic NE release (SCGN boutons), and in heterologous cells. Moreover, our studies demonstrate that Akt is required for insulin regulation of NET. Consistently, in vivo manipulation of insulin signaling in the periphery via STZ treatment results in aberrant Akt signaling in the hippocampus, and this deficit correlates with enhanced NE levels, NET surface expression, and NE clearance. The aberrant NE levels and NET regulation in STZ-induced diabetic mice provide a strong proof of the principle that metabolic dysfunction in the periphery has the potential to impact NET function and monoamine homeostasis in the brain. These data provide one plausible avenue to explain the depressive-like behavioral deficits observed in diabetic rodents (Hilakivi-Clarke et al., 1990). STZ-induced diabetic mice undergo physiological changes beyond hypoinsulinemia, and therefore we cannot exclude the possibility that these changes in NET expression are exclusively due to insulin deficits. Still, our in vitro data strongly indicate a direct role for insulin in regulating NET surface levels. Furthermore, the ability of acute insulin treatment in STZ hippocampal slices to restore NET surface levels and phosphorylation of Akt to control levels, as well as its ability to restore NET function in STZ animals in vivo, support our notion that hypoinsulinemia underlies these alterations. Altogether, these data provide convincing support for an inhibitory role of insulin/Akt signaling in the regulation of NET function, and importantly, this regulation of NET in the brain can be altered by abnormal insulin signaling in the periphery.

Interestingly, this downregulation of NET in response to insulin is contrary to the role of insulin signaling in the regulation of the dopamine transporter (DAT). For example, early studies showed that in vivo manipulation of insulin levels via STZ treatment and food deprivation results in decreased DAT mRNA and DAT-mediated DA uptake, respectively (Figlewicz et al., 1996; Patterson et al., 1998). More recent studies confirm these original observations, and substantial evidence supports the notion that insulin/PI3K/Akt signaling is critical for maintaining basal levels of DAT at the surface (Carvelli et al., 2002; Galici et al., 2003; Garcia et al., 2005; Owens et al., 2005; Zhen et al., 2006; Wei et al., 2007; Williams et al., 2007; Lute et al., 2008; South and Huang, 2008). This ability of insulin to differentially regulate DAT and NET surface expression is intriguing given the high homology of the two transporters, and thus speaks to the specificity of insulin signaling in the regulation of monoamine homeostasis.

In addition to describing the nature of the regulation of NET by insulin, we also establish a novel role for Akt in controlling NET surface availability. We show that Akt inhibition, independent of insulin, in heterologous cells and SCGN boutons results in enhanced NET surface expression. Indeed, overall, our studies show that NET surface expression correlates well with the phos- 
phorylation status of Akt at ser473. Therefore, Akt is not only required for insulin regulation of the transporter, but also manipulation of Akt alone impacts NET surface availability. Distinct signaling pathways such as receptor tyrosine kinase, integrin, and G-protein coupled receptor (GPCR) signaling converge on Akt. Thus, divergent signaling pathways have the potential to similarly impact NET function via Akt signaling as a final common pathway. Indeed, here we demonstrate that similar changes in NET surface availability can be induced by either stimulation of insulin signaling or manipulation of GPCR signaling with an antipsychotic. The ability of the atypical antipsychotic clozapine, which can target $\alpha_{2}$-adrenergic receptors present on presynaptic noradrenergic terminals, to enhance Akt phosphorylation at ser473 is well documented in the cortex (Ashby and Wang, 1996; Emamian et al., 2004; Kang et al., 2004; Karkoulias et al., 2006; Roh et al., 2007). We show that intraperitoneal injection of clozapine not only increases Akt ser 473 phosphorylation, but also, similar to acute insulin treatment, stimulates a subsequent decrease in NET surface expression. These data substantiate the hypothesis that completely distinct signaling pathways that converge on Akt have the potential to similarly influence NET availability and function. In addition, the ability of clozapine to manipulate the surface availability of NET could be important for its enhanced efficacy in the treatment of cognitive symptoms associated with schizophrenia (Woodward et al., 2005). Indeed, a number of clinical trials using NET-specific inhibitors are ongoing and promise to reveal whether NET-specific inhibition will prove effective in treating schizophrenia cognitive symptoms such as poor concentration and memory deficits (clinicaltrials.gov).

The importance of the discovery of Akt as a potent regulator of NET is further emphasized when one considers the wealth of information supporting a role for Akt dysfunction in the development of mental disorders such as schizophrenia and depression. A link between Akt and schizophrenia was first described by Emamian et al. (2004). The authors revealed decreased levels of Akt protein in lymphocytes and postmortem brain tissue from schizophrenic patients along with evidence for a genetic association between schizophrenia and an Akt haplotype. Since these original studies, numerous reports have substantiated an association between Akt dysfunction and schizophrenia (Norton et al., 2007; Arguello and Gogos, 2008; Dawn et al., 2008). In particular, seminal human genetic and imaging studies corroborate a relationship between an Aktl variant associated with schizophrenia and disruptions in DA-associated behaviors linked to the disorder (Tan et al., 2008). These studies indicate possible links among Akt dysregulation, monoamine function, and predisposition to schizophrenia. Correspondingly, our studies provide one molecular mechanism by which Akt dysfunction has the potential to impact monoamine homeostasis, via its regulation of NET, a protein critical for controlling both global NE homeostasis and cortical DA homeostasis (Yamamoto and Novotney, 1998; Moron et al., 2002). Thus, future studies investigating the impact of schizophrenia-linked Akt1 variants on the noradrenergic system (i.e., NET expression and NE homeostasis), and ultimately NE-related behaviors, will strengthen the growing links among aberrant Akt function, monoamine homeostasis, and schizophrenia. Interestingly, related studies from our laboratory in mice show that ablation of phosphorylation of Akt at Ser473 in neurons results in dramatically enhanced NET surface expression as well as behavioral and biochemical phenotypes that are the hallmark characteristics of schizophrenia (Siuta and Robertson et al., 2010).

Although a role for abnormal Akt signaling in schizophrenia is well supported, studies supporting a role for Akt in depression are just beginning to appear. For example, recent studies reveal deficits in Akt activity in the prefrontal cortex postmortem tissue of depressed individuals (Hsiung et al., 2003; Karege et al., 2007). Interestingly, social defeat-induced depression in mice has also been shown to depend on a decrease in Akt activity (Krishnan et al., 2008). Thus, impairments in Akt activity may sustain depression. In addition, chronic antidepressant treatment in both mice and humans results in enhanced levels of phosphorylated Akt (Krishnan et al., 2008), which our studies correlate with decreased surface NET. Interestingly, chronic antidepressant treatment has also been shown to result in a downregulation of NET (Kitayama et al., 2006; Song et al., 2008; Jeannotte et al., 2009a,b). Whether this antidepressant-stimulated decrease in surface NET is Akt dependent, however, remains to be determined. Thus, increases in NET cell surface expression could underlie the etiology of depression. Indeed, one NET SNP F528C that is associated with major depression has enhanced membrane expression of the transporter along with deficits in trafficking of the transporter away from the plasma membrane (Hahn et al., 2005; Haenisch et al., 2008).

Given the widespread influence of NET on monoamine homeostasis in both the CNS and peripheral nervous system, and the evidence supporting a link between NET dysfunction and disease, substantial effort must be invested in enhancing our understanding of NET trafficking and regulation. Here, we show that Akt signaling is key for fine tuning NET surface availability. As our picture of NET regulation becomes more complete, so too will our ability to create unique approaches for treating disorders such as, depression, schizophrenia, drug addiction, and ADHD.

\section{References}

Apparsundaram S, Galli A, DeFelice LJ, Hartzell HC, Blakely RD (1998a) Acute regulation of norepinephrine transport: I. protein kinase C-linked muscarinic receptors influence transport capacity and transporter density in SK-N-SH cells. J Pharmacol Exp Ther 287:733-743.

Apparsundaram S, Schroeter S, Giovanetti E, Blakely RD (1998b) Acute regulation of norepinephrine transport: II. PKC-modulated surface expression of human norepinephrine transporter proteins. J Pharmacol Exp Ther 287:744-751.

Apparsundaram S, Sung U, Price RD, Blakely RD (2001) Traffickingdependent and -independent pathways of neurotransmitter transporter regulation differentially involving p38 mitogen-activated protein kinase revealed in studies of insulin modulation of norepinephrine transport in SK-N-SH cells. J Pharmacol Exp Ther 299:666-677.

Arguello PA, Gogos JA (2008) A signaling pathway AKTing up in schizophrenia. J Clin Invest 118:2018-2021.

Ashby CR Jr, Wang RY (1996) Pharmacological actions of the atypical antipsychotic drug clozapine: a review. Synapse 24:349-394.

Barber M, Kasturi BS, Austin ME, Patel KP, MohanKumar SM, MohanKumar PS (2003) Diabetes-induced neuroendocrine changes in rats: role of brain monoamines, insulin and leptin. Brain Res 964:128-135.

Bell RH Jr, Hye RJ (1983) Animal models of diabetes mellitus: physiology and pathology. J Surg Res 35:433-460.

Bönisch H, Brüss M (2006) The norepinephrine transporter in physiology and disease. Handb Exp Pharmacol 485-524.

Boyd FT Jr, Clarke DW, Muther TF, Raizada MK (1985) Insulin receptors and insulin modulation of norepinephrine uptake in neuronal cultures from rat brain. J Biol Chem 260:15880-15884.

Boyd FT Jr, Clarke DW, Raizada MK (1986) Insulin inhibits specific norepinephrine uptake in neuronal cultures from rat brain. Brain Res 398:1-5.

Carvelli L, Morón JA, Kahlig KM, Ferrer JV, Sen N, Lechleiter JD, LeebLundberg LM, Merrill G, Lafer EM, Ballou LM, Shippenberg TS, Javitch JA, Lin RZ, Galli A (2002) PI 3-kinase regulation of dopamine uptake. J Neurochem 81:859-869.

Daws LC, Montanez S, Owens WA, Gould GG, Frazer A, Toney GM, Gerhardt GA (2005) Transport mechanisms governing serotonin clear- 
ance in vivo revealed by high-speed chronoamperometry. J Neurosci Methods 143:49-62.

DeFeo-Jones D, Barnett SF, Fu S, Hancock PJ, Haskell KM, Leander KR, McAvoy E, Robinson RG, Duggan ME, Lindsley CW, Zhao Z, Huber HE, Jones RE (2005) Tumor cell sensitization to apoptotic stimuli by selective inhibition of specific Akt/PKB family members. Mol Cancer Ther 4:271-279.

Dipace C, Sung U, Binda F, Blakely RD, Galli A (2007) Amphetamine induces a calcium/calmodulin-dependent protein kinase II-dependent reduction in norepinephrine transporter surface expression linked to changes in syntaxin 1A/transporter complexes. Mol Pharmacol 71: $230-239$.

Dummler B, Hemmings BA (2007) Physiological roles of PKB/Akt isoforms in development and disease. Biochem Soc Trans 35:231-235.

Easton RM, Cho H, Roovers K, Shineman DW, Mizrahi M, Forman MS, Lee VM, Szabolcs M, de Jong R, Oltersdorf T, Ludwig T, Efstratiadis A, Birnbaum MJ (2005) Role for Akt3/protein kinase Bgamma in attainment of normal brain size. Mol Cell Biol 25:1869-1878.

Emamian ES, Hall D, Birnbaum MJ, Karayiorgou M, Gogos JA (2004) Convergent evidence for impaired AKT1-GSK3beta signaling in schizophrenia. Nat Genet 36:131-137.

Figlewicz DP, Bentson K, Ocrant I (1993) The effect of insulin on norepinephrine uptake by PC12 cells. Brain Res Bull 32:425-431.

Figlewicz DP, Brot MD, McCall AL, Szot P (1996) Diabetes causes differential changes in CNS noradrenergic and dopaminergic neurons in the rat: a molecular study. Brain Res 736:54-60.

Galici R, Galli A, Jones DJ, Sanchez TA, Saunders C, Frazer A, Gould GG, Lin RZ, France CP (2003) Selective decreases in amphetamine selfadministration and regulation of dopamine transporter function in diabetic rats. Neuroendocrinology 77:132-140.

Ganguly PK, Dhalla KS, Innes IR, Beamish RE, Dhalla NS (1986) Altered norepinephrine turnover and metabolism in diabetic cardiomyopathy. Circ Res 59:684-693.

Garcia BG, Wei Y, Moron JA, Lin RZ, Javitch JA, Galli A (2005) Akt is essential for insulin modulation of amphetamine-induced human dopamine transporter cell-surface redistribution. Mol Pharmacol 68:102-109.

Haenisch B, Linsel K, Brüss M, Gilsbach R, Propping P, Nöthen MM, Rietschel M, Fimmers R, Maier W, Zobel A, Höfels S, Guttenthaler V, Göthert M, Bönisch H (2009) Association of major depression with rare functional variants in norepinephrine transporter and serotonin1A receptor genes. Am J Med Genet B Neuropsychiatr Genet 150B:1013-1016

Hahn MK, Robertson D, Blakely RD (2003) A mutation in the human norepinephrine transporter gene (SLC6A2) associated with orthostatic intolerance disrupts surface expression of mutant and wild-type transporters. J Neurosci 23:4470-4478.

Hahn MK, Mazei-Robison MS, Blakely RD (2005) Single nucleotide polymorphisms in the human norepinephrine transporter gene affect expression, trafficking, antidepressant interaction, and protein kinase $\mathrm{C}$ regulation. Mol Pharmacol 68:457-466.

Hahn MK, Blackford JU, Haman K, Mazei-Robison M, English BA, Prasad HC, Steele A, Hazelwood L, Fentress HM, Myers R, Blakely RD, SandersBush E, Shelton R (2008) Multivariate permutation analysis associates multiple polymorphisms with subphenotypes of major depression. Genes Brain Behav 7:487-495.

Hahn MK, Steele A, Couch RS, Stein MA, Krueger JJ (2009) Novel and functional norepinephrine transporter protein variants identified in attentiondeficit hyperactivity disorder. Neuropharmacology 57:694-701

Halushka MK, Fan JB, Bentley K, Hsie L, Shen N, Weder A, Cooper R, Lipshutz R, Chakravarti A (1999) Patterns of single-nucleotide polymorphisms in candidate genes for blood-pressure homeostasis. Nat Genet 22:239-247.

He A, Liu X, Liu L, Chang Y, Fang F (2007) How many signals impinge on GLUT4 activation by insulin? Cell Signal 19:1-7.

Hernandez L, Briese E (1972) Analysis of diabetic hyperphagia and polydipsia. Physiol Behav 9:741-746.

Hilakivi-Clarke LA, Wozniak KM, Durcan MJ, Linnoila M (1990) Behavior of streptozotocin-diabetic mice in tests of exploration, locomotion, anxiety, depression and aggression. Physiol Behav 48:429-433.

Hsiung SC, Adlersberg M, Arango V, Mann JJ, Tamir H, Liu KP (2003) Attenuated 5-HT1A receptor signaling in brains of suicide victims: involvement of adenylyl cyclase, phosphatidylinositol 3-kinase, Akt and mitogen-activated protein kinase. J Neurochem 87:182-194.
Iversen LL (1971) Role of transmitter uptake mechanisms in synaptic neurotransmission. Br J Pharmacol 41:571-591.

Jayanthi LD, Samuvel DJ, Ramamoorthy S (2004) Regulated internalization and phosphorylation of the native norepinephrine transporter in response to phorbol esters. Evidence for localization in lipid rafts and lipid raft-mediated internalization. J Biol Chem 279:19315-19326.

Jeannotte AM, McCarthy JG, Redei EE, Sidhu A (2009a) Desipramine modulation of alpha-, gamma-synuclein, and the norepinephrine transporter in an animal model of depression. Neuropsychopharmacology 34: 987-998.

Jeannotte AM, McCarthy JG, Sidhu A (2009b) Desipramine induced changes in the norepinephrine transporter, alpha- and gamma-synuclein in the hippocampus, amygdala and striatum. Neurosci Lett 467:86-89.

Kang UG, Seo MS, Roh MS, Kim Y, Yoon SC, Kim YS (2004) The effects of clozapine on the GSK-3-mediated signaling pathway. FEBS Lett 560: $115-119$.

Karege F, Perroud N, Burkhardt S, Schwald M, Ballmann E, La Harpe R, Malafosse A (2007) Alteration in kinase activity but not in protein levels of protein kinase B and glycogen synthase kinase-3[beta] in ventral prefrontal cortex of depressed suicide victims. Biol Psychiatry 61:240-245.

Karkoulias G, Mastrogianni O, Lymperopoulos A, Paris H, Flordellis C (2006) alpha(2)-Adrenergic receptors activate MAPK and Akt through a pathway involving arachidonic acid metabolism by cytochrome P450dependent epoxygenase, matrix metalloproteinase activation and subtype-specific transactivation of EGFR. Cell Signal 18:729-739.

Kim CH, Hahn MK, Joung Y, Anderson SL, Steele AH, Mazei-Robinson MS, Gizer I, Teicher MH, Cohen BM, Robertson D, Waldman ID, Blakely RD, Kim KS (2006) A polymorphism in the norepinephrine transporter gene alters promoter activity and is associated with attention-deficit hyperactivity disorder. Proc Natl Acad Sci U S A 103:19164-19169.

Kitayama T, Song L, Morita K, Morioka N, Dohi T (2006) Down-regulation of norepinephrine transporter function induced by chronic administration of desipramine linking to the alteration of sensitivity of local-anestheticsinduced convulsions and the counteraction by co-administration with local anesthetics. Brain Res 1096:97-103.

Klimek V, Stockmeier C, Overholser J, Meltzer HY, Kalka S, Dilley G, Ordway GA (1997) Reduced levels of norepinephrine transporters in the locus coeruleus in major depression. J Neurosci 17:8451-8458.

Krishnan V, Han MH, Mazei-Robison M, Iñiguez SD, Ables JL, Vialou V, Berton O, Ghose S, Covington HE 3rd, Wiley MD, Henderson RP, Neve RL, Eisch AJ, Tamminga CA, Russo SJ, Bolaños CA, Nestler EJ (2008) AKT Signaling within the Ventral Tegmental Area Regulates Cellular and Behavioral Responses to Stressful Stimuli. Biological Psychiatry 64:691-700.

Lapierre LA, Kumar R, Hales CM, Navarre J, Bhartur SG, Burnette JO, Provance DW Jr, Mercer JA, Bähler M, Goldenring JR (2001) Myosin vb is associated with plasma membrane recycling systems. Mol Biol Cell 12:1843-1857.

Lenzen S (2008) The mechanisms of alloxan- and streptozotocin-induced diabetes. Diabetologia 51:216-226.

Li Q, Lau A, Morris TJ, Guo L, Fordyce CB, Stanley EF (2004) A syntaxin 1, Galpha(o), and N-type calcium channel complex at a presynaptic nerve terminal: analysis by quantitative immunocolocalization. J Neurosci 24:4070-4081.

Lindsley CW, Zhao Z, Leister WH, Robinson RG, Barnett SF, Defeo-Jones D, Jones RE, Hartman GD, Huff JR, Huber HE, Duggan ME (2005) Allosteric Akt (PKB) inhibitors: discovery and SAR of isozyme selective inhibitors. Bioorg Med Chem Lett 15:761-764.

Lustman PJ, Clouse RE (2005) Depression in diabetic patients: the relationship between mood and glycemic control. J Diabetes Complications 19:113-122.

Lute BJ, Khoshbouei H, Saunders C, Sen N, Lin RZ, Javitch JA, Galli A (2008) PI3K signaling supports amphetamine-induced dopamine efflux. Biochem Biophys Res Commun 372:656-661.

Manning BD, Cantley LC (2007) AKT/PKB signaling: navigating downstream. Cell 129:1261-1274.

Masters BA, Shemer J, Judkins JH, Clarke DW, Le Roith D, Raizada MK (1987) Insulin receptors and insulin action in dissociated brain cells. Brain Res 417:247-256.

Matthies HJ, Han Q, Shields A, Wright J, Moore JL, Winder DG, Galli A, Blakely RD (2009) Subcellular localization of the antidepressantsensitive norepinephrine transporter. BMC Neurosci 10:65. 
Matthies HJ, Moore JL, Saunders C, Matthies DS, Lapierre LA, Goldenring JR, Blakely RD, Galli A (2010) Rab11 supports amphetamine-stimulated norepinephrine transporter trafficking. J Neurosci 30:7863-7877.

Miner LH, Schroeter S, Blakely RD, Sesack SR (2003) Ultrastructural localization of the norepinephrine transporter in superficial and deep layers of the rat prelimbic prefrontal cortex and its spatial relationship to probable dopamine terminals. J Comp Neurol 466:478-494.

Morón JA, Brockington A, Wise RA, Rocha BA, Hope BT (2002) Dopamine uptake through the norepinephrine transporter in brain regions with low levels of the dopamine transporter: evidence from knock-out mouse lines. J Neurosci 22:389-395.

Mukherjee S, Schnur DB, Reddy R (1989) Family history of type 2 diabetes in schizophrenic patients. Lancet 1:495.

Mukherjee S, Decina P, Bocola V, Saraceni F, Scapicchio PL (1996) Diabetes mellitus in schizophrenic patients. Compr Psychiatry 37:68-73.

Norton N, Williams HJ, Dwyer S, Carroll L, Peirce T, Moskvina V, Segurado R, Nikolov I, Williams NM, Ikeda M, Iwata N, Owen MJ, O'Donovan MC (2007) Association analysis of AKT1 and schizophrenia in a UK case control sample. Schizophr Res 93:58-65.

Owens WA, Sevak RJ, Galici R, Chang X, Javors MA, Galli A, France CP, Daws LC (2005) Deficits in dopamine clearance and locomotion in hypoinsulinemic rats unmask novel modulation of dopamine transporters by amphetamine. J Neurochem 94:1402-1410

Pacholczyk T, Blakely RD, Amara SG (1991) Expression cloning of a cocaine- and antidepressant-sensitive human noradrenaline transporter. Nature 350:350-354.

Patterson TA, Brot MD, Zavosh A, Schenk JO, Szot P, Figlewicz DP (1998) Food deprivation decreases mRNA and activity of the rat dopamine transporter. Neuroendocrinology 68:11-20.

Raizada MK, Shemer J, Judkins JH, Clarke DW, Masters BA, LeRoith D (1988) Insulin receptors in the brain: structural and physiological characterization. Neurochem Res 13:297-303.

Roh MS, Seo MS, Kim Y, Kim SH, Jeon WJ, Ahn YM, Kang UG, Juhnn YS, Kim YS (2007) Haloperidol and clozapine differentially regulate signals upstream of glycogen synthase kinase 3 in the rat frontal cortex. Exp Mol Med 39:353-360.

Rumantir MS, Kaye DM, Jennings GL, Vaz M, Hastings JA, Esler MD (2000) Phenotypic evidence of faulty neuronal norepinephrine reuptake in essential hypertension. Hypertension 36:824-829.

Savchenko V, Sung U, Blakely RD (2003) Cell surface trafficking of the antidepressant-sensitive norepinephrine transporter revealed with an ectodomain antibody. Mol Cell Neurosci 24:1131-1150.

Shannon JR, Flattem NL, Jordan J, Jacob G, Black BK, Biaggioni I, Blakely RD, Robertson D (2000) Orthostatic intolerance and tachycardia associated with norepinephrine-transporter deficiency. N Engl J Med 342:541-549.

She QB, Chandarlapaty S, Ye Q, Lobo J, Haskell KM, Leander KR, DeFeoJones D, Huber HE, Rosen N (2008) Breast tumor cells with PI3K mutation or HER2 amplification are selectively addicted to Akt signaling. PLoS One 3:e3065.

Shimizu H (1991) Alteration in hypothalamic monoamine metabolism of freely moving diabetic rat. Neurosci Lett 131:225-227.

Siuta MA, Robertson SD, Kocalis H, Saunders C, Gresch PJ, Khatri V, Shiota C, Kennedy JP, Lindsley CW, Daws LC, Polley DB, Veenstra-Vanderweele J, Stanwood GD, Magnuson MA, Niswender KD, Galli A (2010) Dysregulation of the norepinephrine transporter sustains cortical hypodopaminergia and schizophrenia-like behaviors in neuronal rictor null mice. PLoS Biol 8:e1000393.
Song L, Kitayama T, Morita K, Morioka N, Dohi T (2008) Down-regulation of norepinephrine transporter expression on membrane surface induced by chronic administration of desipramine and the antagonism by coadministration of local anesthetics in mice. Neurochem Int 52:826-833.

South T, Huang XF (2008) High-fat diet exposure increases dopamine D2 receptor and decreases dopamine transporter receptor binding density in the nucleus accumbens and caudate putamen of mice. Neurochem Res 33:598-605.

Sung U, Apparsundaram S, Galli A, Kahlig KM, Savchenko V, Schroeter S, Quick MW, Blakely RD (2003) A regulated interaction of syntaxin 1A with the antidepressant- sensitive norepinephrine transporter establishes catecholamine clearance capacity. J Neurosci 23:1697-1709.

Tan HY, Nicodemus KK, Chen Q, Li Z, Brooke JK, Honea R, Kolachana BS, Straub RE, Meyer-Lindenberg A, Sei Y, Mattay VS, Callicott JH, Weinberger DR (2008) Genetic variation in AKT1 is linked to dopamineassociated prefrontal cortical structure and function in humans. J Clin Invest 118:2200-2208.

Thiselton DL, Vladimirov VI, Kuo PH, McClay J, Wormley B, Fanous A, O’Neill FA, Walsh D, Van den Oord EJ, Kendler KS, Riley BP (2008) AKT1 is associated with schizophrenia across multiple symptom dimensions in the Irish study of high density schizophrenia families. Biol Psychiatry 63:449-457.

Toney GM, Daws LC (2006) Juxtacellular labeling and chemical phenotyping of extracellulary recorded neurons in vivo. Methods Mol Biol 337:127137.

Uchida J, Kiuchi Y, Ohno M, Yura A, Oguchi K (1998) Ca(2+)-dependent enhancement of $[3 \mathrm{H}]$ noradrenaline uptake in $\mathrm{PC1} 2$ cells through calmodulin-dependent kinases. Brain Res 809:155-164.

Wei Y, Williams JM, Dipace C, Sung U, Javitch JA, Galli A, Saunders C (2007) Dopamine transporter activity mediates amphetamine-induced inhibition of Akt through a Ca2+/calmodulin-dependent kinase IIdependent mechanism. Mol Pharmacol 71:835-842.

Wersinger C, Jeannotte A, Sidhu A (2006) Attenuation of the norepinephrine transporter activity and trafficking via interactions with alphasynuclein. Eur J Neurosci 24:3141-3152.

Williams JM, Owens WA, Turner GH, Saunders C, Dipace C, Blakely RD, France CP, Gore JC, Daws LC, Avison MJ, Galli A (2007) Hypoinsulinemia regulates amphetamine-induced reverse transport of dopamine. PLoS Biol 5:e274.

Woodward ND, Purdon SE, Meltzer HY, Zald DH (2005) A meta-analysis of neuropsychological change to clozapine, olanzapine, quetiapine, and risperidone in schizophrenia. Int J Neuropsychopharmacol 8:457-472.

Xu F, Gainetdinov RR, Wetsel WC, Jones SR, Bohn LM, Miller GW, Wang YM, Caron MG (2000) Mice lacking the norepinephrine transporter are supersensitive to psychostimulants. Nat Neurosci 3:465-471.

Yamamoto BK, NovotneyS (1998) Regulation of extracellular dopamine by the norepinephrine transporter. J Neurochem 71:274-280.

Zaid H, Antonescu CN, Randhawa VK, Klip A (2008) Insulin action on glucose transporters through molecular switches, tracks and tethers. Biochem J 413:201-215.

Zhao Z, Ksiezak-Reding H, Riggio S, Haroutunian V, Pasinetti GM (2006) Insulin receptor deficits in schizophrenia and in cellular and animal models of insulin receptor dysfunction. Schizophr Res 84:1-14.

Zhen J, Reith ME, Carr KD (2006) Chronic food restriction and dopamine transporter function in rat striatum. Brain Res 1082:98-101. 